\title{
Diferencias de crecimiento entre los estados de la frontera norte de México: una explicación*
}

\author{
Juan Manuel Ocegueda Hernández,** Rogelio Varela Llamas*** \\ y Ramón Castillo Ponce****
}

\section{RESUMEN}

Se realiza un análisis de las diferencias entre las tasas de crecimiento de las seis entidades de la frontera norte de México durante el periodo 1993-2010 y se propone una explicación que destaca el papel del fenómeno migratorio, cuyos efectos sobre la población económicamente activa y la dinámica demográfica incidieron en la estructura del empleo en cada uno de los estados estudiados. Asimismo, se enfatiza el rol que jugaron las diferencias en la inversión pública y su posible impacto sobre el dinamismo de la inversión privada, lo que inhibió la generación de empleo en el sector formal de la economía. La conjunción de ambos fenómenos dio lugar a una proliferación de actividades de baja productividad, particularmente de aquéllas vinculadas a la informalidad y al sector del hogar, cuyos efectos sobre el crecimiento estuvieron condicionados por la magnitud y la manera como dichos fenómenos interactuaron.

Palabras clave: análisis de economías regionales, crecimiento económico, tendencias demográficas, inversión pública, productividad sectorial.

Clasificación JEL: R13, O40, J11, H54, O47.

\section{Abstract}

The differences in economic growth rates among the six states of the northern border of Mexico on 1993-2010 are analyzed and an explanation is proposed that highlights the role of the migration through its effects on amount of labor force and population, which affected the employment structure in all of the border states. It also emphasizes the role played by the differences in public investment and its possible effects on the private investment, which decreased new jobs in the formal sector of the economy. Both phenomena increased low-productivity activities, specially those related to the informal and household sector, which effects on growth were conditioned by the magnitude and how these events interacted.

Keywords: regional economies analysis, economic growth, demographic trends, public investment, productivity of economic sectors

JEL classification: R13, O40, J11, H54, O47.

* Fecha de recepción: 05/10/2012. Fecha de aprobación: 04/09/2014.

** Profesor de tiempo completo de la Facultad de Economía y Relaciones Internacionales de la Universidad Autónoma de Baja California y miembro del Sistema Nacional de Investigadores. Correo electrónico: jmocegueda@uabc.edu.mx.

*** Profesor de tiempo completo de la Facultad de Economía y Relaciones Internacionales de la Universidad Autónoma de Baja California y miembro del Sistema Nacional de Investigadores. Correo electrónico: rvarela@uabc.edu.mx.

**** Profesor de tiempo completo de la Facultad de Economía y Relaciones Internacionales de la Universidad Autónoma de Baja California y miembro del Sistema Nacional de Investigadores. Correo electrónico: racastillo2000@yahoo.com 


\section{INTRODUCCIÓN}

La frontera norte de México se ha caracterizado durante las últimas dos décadas por su sobresaliente desempeño económico, el cual contrasta con los pobres resultados obtenidos en otras regiones del país. Sin embargo, el crecimiento de estas entidades fronterizas no ha sido homogéneo: entre 1993 y 2010, Coahuila registró un aumento de su producto interno bruto (PIB) per cápita de $2.2 \%$ anual, una de las tasas más altas del país. Le siguieron Nuevo León, con una tasa de $1.6 \%$ anual, y luego Chihuahua, Sonora y Tamaulipas, todas con $1.5 \%$. Baja California se ubicó en la sexta posición con un crecimiento de $0.3 \%$ anual, siendo el único caso en que el crecimiento estuvo por debajo de la media nacional, de $1.1 \%$ para el mismo periodo.

El comportamiento económico diferenciado ha implicado una redistribución del ingreso nacional y regional, con el consecuente reposicionamiento favorable de cinco de las seis entidades cuando se comparan las cifras del PIB por habitante de 2010 con las de 1993, con Baja California como la única que empeora su situación. Si se toma como referencia el porcentaje que representa el ingreso de cada estado con respecto al de la entidad de mayor desarrollo en el país, el Distrito Federal, se observa que Coahuila pasó de $49.3 \%$ a $58.7 \%$; Nuevo León, de $67.2 \%$ a $71.7 \%$; Chihuahua, de $51.7 \%$ a $54.3 \%$; Tamaulipas, de $40.3 \%$ a $42.4 \%$, y Sonora, de $46.7 \%$ a $49.1 \%$, mientras que Baja California pasó de $52.9 \%$ a $45.2 \%$. Cuando se considera la región en su conjunto, se muestra un avance de $51.3 \%$ a $53.6 \%$, lo que implica un proceso de convergencia con relación al Distrito Federal que, fuera de los estados fronterizos, sólo se observa en la zona centro-norte ${ }^{1}$.

El patrón de crecimiento económico seguido por la frontera norte ha sido estudiado por varios autores con distintos enfoques. Mendoza (2002), por ejemplo, señala que ha sido condicionado por el impacto de la especialización manufacturera de sus principales ciudades, las cuales se beneficiaron con las externalidades asociadas a las economías de aglomeración industrial después de la apertura comercial, principalmente por sus ventajas geográficas. Sin embargo, también documenta el debilitamiento de este efecto en la segunda mitad de los noventa. De León $(2000,2008)$, advierte sobre un proceso de desaceleración en el crecimiento de la productividad manufacturera que ocurre al mismo tiempo

${ }^{1}$ La zona centro-norte, usando la clasificación de Esquivel (1999), comprende Aguascalientes, Durango, Guanajuato, Querétaro, San Luis Potosí y Zacatecas. 
que se da una fuerte expansión del empleo, principalmente en la industria maquiladora, un patrón que se repite a lo largo del país y que podría estar detrás del lento crecimiento registrado en las últimas décadas. No obstante, de acuerdo con lo encontrado en este trabajo, no parece ser un resultado generalizable a toda la región y sí, por el contrario, se puede sostener que existen tendencias diferenciadas por entidad federativa. Por su parte, Ocegueda, Escamilla y Mungaray (2011) sostienen que la trayectoria de crecimiento seguida por la región después del Tratado de Libre Comercio de América del Norte (TLCAN) está estrechamente vinculada a los cambios en su estructura productiva y al modelo de especialización resultante, cuya característica principal es una contracción en la participación de la industria manufacturera no maquiladora dentro del empleo y la producción regional.

Con la finalidad de generar nueva información que contribuya a la mejor comprensión de la dinámica económica fronteriza, este trabajo busca aportar argumentos explicativos adicionales para comprender por qué en las últimas dos décadas los estados de la región han tenido desempeños económicos distintos, recurriendo para ello a la orientación que proporciona la propia teoría económica. La hipótesis que se sostiene es que las diferencias registradas en el incremento del PIB se explican principalmente por el impacto económico y demográfico que tuvieron los flujos migratorios, así como por las tasas a las que creció la inversión pública y sus posibles efectos sobre la inversión privada, además de los ritmos a los que se expandió la ocupación en actividades de baja productividad, lo cual estuvo condicionado por la interacción de los factores señalados y por las presiones que ello generó sobre el mercado de trabajo. Las diversas maneras en que se combinaron estos elementos y la forma como éstos interactuaron determinaron distintas trayectorias para la inversión por trabajador, la productividad laboral y el PIB per cápita.

Además de la introducción, el documento está constituido por cinco apartados: en el primero, se revisan los principales argumentos teóricos que explican las diferencias en tasas de crecimiento, tomando en consideración algunas de las posiciones más importantes en el debate actual. En el segundo, se propone una tipología de patrones de crecimiento y se realiza un esfuerzo por aplicarla a las entidades fronterizas. En el tercero, se interpretan algunas cifras estadísticas disponibles que describen el desempeño de la región, así como los cambios en las principales variables utilizadas en este estudio. En el cuarto, se presenta el análisis econométrico con una descripción de los aspectos metodológicos relevantes y la interpretación de los resultados. En el último apartado, se presentan 
algunas reflexiones sobre los hallazgos de esta investigación a manera de conclusiones.

\section{DETERMINANTES DEL CRECIMIENTO ECONÓMICO}

\section{Acumulación de factores y aumento de la productividad}

Una de las conclusiones del debate reciente en la teoría del crecimiento es que la acumulación de factores, tanto en forma de capital físico como humano, junto con la innovación tecnológica, son las fuerzas que dirigen el crecimiento económico. Sin embargo, los argumentos para llegar a esta conclusión y los canales a través de los cuales se postula que interactúan las variables asociadas a estos procesos, difieren de acuerdo con la escuela del pensamiento de que se trate. Esta visión se aleja del viejo modelo neoclásico (VMN) desarrollado por Solow (1956) por lo menos en dos aspectos fundamentales: primero, en el vMN, la acumulación de factores sólo tiene efectos de nivel sobre el ingreso por habitante de largo plazo; segundo, en el vMN, la innovación y el incremento en la productividad total de los factores asociado depende de acontecimientos fortuitos en el ámbito de la ciencia y la tecnología, y no de inversiones sistemáticas e intencionadas que se orienten a la generación de conocimientos. Esto supone una ausencia de vínculos entre la política económica y el crecimiento que deja una gran insatisfacción, pues implica que no se puede hacer nada para mejorar el desempeño económico de largo plazo.

La idea de que la acumulación de capital físico importa se remonta a los trabajos pioneros de Harrod (1939) y Domar (1946), en donde se asume una relación proporcional entre la tasa de inversión (inversión/PIB) y la tasa de crecimiento del PIB. El modelo resultante de estos trabajos fue utilizado durante muchos años en ejercicios de planeación financiera que, desde el Banco Mundial, intentaban determinar las necesidades de financiamiento de los países pobres, con la finalidad de alcanzar niveles de inversión compatibles con tasas de crecimiento deseadas. En un documento posterior, Kaldor (1957) formula un modelo en donde la inversión en máquinas, que depende positivamente de la distribución del ingreso en favor de los beneficios, incrementa la productividad laboral al acelerar la incorporación de los avances tecnológicos y promover el aprendizaje por experiencia en las actividades productivas. En éste, la acumulación de capital físico y los incrementos en la productividad se retroalimentan mutuamente, lo que permite considerar endógena la tasa de progreso técnico. 
El vínculo entre inversión física y crecimiento está presente también en Lewis (1954), quien destaca el carácter dual de las economías subdesarrolladas como un elemento central que define su trayectoria hacia un equilibrio de estado estacionario, a través de una ruta diferente a la que sugiere el vMN. En su opinión, el camino al desarrollo pasa por la industrialización y ésta se puede alentar promoviendo nuevas inversiones en el sector manufacturero que aprovechen la abundante mano de obra que por un periodo prolongado puede proveer el sector tradicional. Por su parte, Rostow (1960) define cinco etapas del crecimiento, de las cuales la primera corresponde al "despegue", cuyo principal ingrediente es un gran esfuerzo inicial de inversión. Rosenstein-Rodan (1943), mediante un razonamiento parecido basado en su teoría del "gran empujón", sostiene que el estancamiento de los países pobres puede superarse a través de un programa coordinado de grandes inversiones públicas y privadas que permitan aprovechar favorablemente los rendimientos crecientes de las actividades modernas y la gran disponibilidad de trabajo que caracteriza a estas economías.

La relación entre acumulación de capital humano y crecimiento económico se desarrolló por primera vez por Lucas (1988). La principal idea en su trabajo es que la reproducción del capital físico (к) es guiada por la disponibilidad de capital humano (H), el que a su vez puede producirse sin límites y en proporción directa a los recursos que la sociedad y los individuos destinen para este fin. Si se supone que la inversión en $\mathrm{H}$ es una fracción fija del PIB, que la producción de capital humano se realiza sólo con $\mathrm{H}$ mientras que la de bienes se lleva a cabo con $\mathrm{K}$ y H, ambas funciones bajo condiciones de rendimientos constantes a escala, se puede demostrar que el proceso de acumulación se sostiene indefinidamente sin necesidad de progreso técnico exógeno. Romer (1986) propone una versión alternativa basada en la acumulación de conocimientos que se difunden a través de externalidades, mientras que en Romer (1990) es a través de la inversión social en actividades de investigación científica y desarrollo tecnológico. La idea central es que la producción de conocimientos es una actividad especial en la que los rendimientos sociales superan a los privados, lo que garantiza altas tasas de rentabilidad que sostienen el proceso de acumulación de capital en el tiempo.

El enfoque Lucas-Romer fue muy influyente en los noventa y principios del siglo XXI dando lugar a la nueva teoría del crecimiento (NTC) que, alejándose del VMN, estableció una conexión de causalidad entre política económica y crecimiento. En su opinión, invertir no es suficiente para crecer, es necesario, además, que esto se realice eficientemente mediante la adopción de políticas de libre mer- 
cado, la reducción del tamaño del gobierno y el mantenimiento de los precios relativos correctos o de equilibrio (Obregón, 2008). Asimismo, se destaca la importancia de la especialización en áreas productivas con altas tasas de aprendizaje y externalidades tecnológicas, y en las que el progreso técnico es endógeno, sosteniendo que los países con orientación productiva hacia los bienes de alto contenido tecnológico pueden crecer más rápido que aquellos que producen bienes de tipo tradicional, debido a que sus oportunidades de innovación son mayores (Romer, 1990; Grossman y Helpman, 1991).

La especialización es una vía que vincula la acumulación de factores con la innovación técnica y que no es exclusiva de la NTC; en realidad, casi todos los autores que se mencionan en párrafos anteriores sostienen que la industrialización promueve el crecimiento. En la literatura postkeynesiana se sostiene que la especialización en actividades con rendimientos crecientes a escala acelera el incremento de la productividad en el conjunto de la economía, ya sea como resultado del progreso técnico inducido o por la absorción de recursos provenientes de actividades menos productivas (Kaldor, 1966; 1970). Asimismo, puede tener efectos favorables sobre el crecimiento económico cuando se orienta a la producción de bienes con altas elasticidades ingreso, debido a que eleva la competitividad en el comercio internacional y permite la apropiación de una fracción creciente de la demanda externa a medida que ésta se expande (Thirlwall, 1979; Thirlwall y Dixon, 1979).

Las dificultades para conciliar la teoría con una evidencia empírica internacional compleja y heterogénea, así como la obtención de resultados diferentes en la aplicación de políticas económicas similares, favoreció en los noventa el desarrollo de la nueva escuela institucionalista, según la cual, el dinamismo de la inversión, la producción de capital humano y de conocimientos, la capacidad para innovar y la eficacia misma de las políticas implementadas dependen del entramado institucional que soporta las transacciones económicas (Rodrik, 2008). Ciertos arreglos institucionales favorecen más que otros la inversión productiva y la innovación, particularmente aquellos que fomentan la educación, combaten la desigualdad y la pobreza, y proporcionan un marco jurídico que protege los derechos de propiedad sobre los bienes y las ideas, así como un aparato de justicia que garantiza la seguridad publica (North, 1990).

La literatura referida se puede sintetizar en tres ideas principales acerca de las fuerzas que impulsan el progreso técnico: en primer lugar, la acumulación de capital, a través de la sustitución de máquinas y equipo obsoleto que permite incorporar los avances científico-tecnológicos; las mejoras en la organización de 
los procesos productivos se atribuyen a los aumentos en la escala de la producción o mediante procesos de aprendizaje que elevan la productividad laboral para un mismo acervo de capital, a medida que aumentan la producción y la experiencia. En segundo lugar, la inversión de recursos que la sociedad realiza para formar capital humano y producir nuevos conocimientos, así como las políticas empleadas para incentivar la innovación. En tercer término, el tipo de actividades productivas que se desarrollan y que ofrecen oportunidades diferenciadas para el aprendizaje, la innovación técnica y el acceso a mercados en expansión. Todas estas fuerzas son impulsadas o inhibidas por el entramado institucional que subyace en cada país o región (Ocegueda, 2000).

\section{Demografia, migración y crecimiento}

La literatura sobre crecimiento económico ha destacado la importancia de los factores demográficos, aunque sus efectos y las vías a través de las cuales impactan en el desempeño de las economías difieren de una teoría a otra. En el vMn, la expansión poblacional contrae el ingreso per cápita en el equilibrio de largo plazo, pero no la tasa a la que éste crece, la cual es determinada exclusivamente por el progreso técnico exógeno. En contraposición, la NTC establece un vínculo positivo entre tamaño y aumento de la población con respecto a la tasa de crecimiento del PIB per cápita, lo cual se asocia con efectos de escala que derivan de externalidades asociadas al capital agregado de la economía (Romer, 1986) o con la introducción de una función de producción de conocimientos en la que el factor trabajo corresponde a una fracción constante de la población (Romer, 1990). Si bien este resultado ha sido polémico y difícil de conciliar con la experiencia internacional para explicar diferencias en las tasas de crecimiento entre países, Kremer (1993) demuestra que cuando esta idea se aplica al mundo como una sola economía y considerando periodos de tiempo muy largos, por ejemplo, varios siglos, dicho resultado se vuelve consistente con la evidencia empírica, encontrándose una fuerte correlación estadística entre el tamaño de la población y el PIB per cápita, así como entre sus respectivas tasas de crecimiento.

Un mayor dinamismo demográfico puede afectar de manera negativa el crecimiento si éste es impulsado por la tasa de ahorro, toda vez que un mayor tamaño poblacional aumenta el consumo agregado y su participación dentro del PIB, así como la tasa de dependencia en las familias y en la sociedad (población total/población ocupada), lo que a su vez inhibe el incremento del ingreso per cápita. Asimismo, su impacto sobre los flujos migratorios puede alterar la 
trayectoria de largo plazo de la economía, aunque el sentido en que ésta se modifica no está claro y depende de la composición de la población migrante y de las condiciones económicas generales de las zonas expulsoras y receptoras. Ahora bien, el fenómeno migratorio, en la medida en que conlleva a una redistribución espacial de personas y familias, incide en el comportamiento demográfico en las áreas geográficas que se ven afectadas, estableciéndose una relación endógena entre aumento poblacional y migración cuando se analiza desde una perspectiva regional.

La relación entre migración y crecimiento es compleja y bidireccional: una región exitosa que ofrece empleos bien remunerados atrae a personas de otras latitudes que no encuentran las mismas oportunidades en sus lugares de origen; a su vez, la disponibilidad de mano de obra abundante atrae nuevas inversiones que fortalecen la situación económica inicial. Lo contrario ocurre en la zona geográfica expulsora, casi siempre más pobre, en donde la pérdida de mano de obra joven y la frecuente condición que las caracteriza de contar con una mayor expansión demográfica modifican desfavorablemente la tasa de dependencia acentuando las condiciones iniciales de pobreza (Myrdal, 1970). Esta secuencia de hechos describe una dinámica acumulativa circular que ha sido destacada por otros autores; por ejemplo, Kaldor $(1966 ; 1970)$ cuando formula las tres leyes que llevan su nombre sostiene que el acceso a una oferta laboral abundante en las regiones económicamente más dinámicas, parte de la cual puede ser provista por la migración, permite aprovechar las ventajas asociadas con la expansión de sectores y actividades que operan con rendimientos crecientes, lo cual contribuye a elevar la tasa de crecimiento del producto por periodos prolongados.

En los planteamientos anteriores subyace la idea de que la migración favorece el desempeño económico de las zonas receptoras y perjudica a las expulsoras, siendo una de las razones principales las transferencias de capital humano que se dan entre unas y otras. Sin embargo, existen circunstancias en las que este mecanismo puede fallar ocasionando un resultado diferente, particularmente cuando la inversión no aumenta en proporción a los flujos de mano de obra en las áreas que reciben migrantes, en cuyo caso crecen el subempleo y el desempleo al mismo tiempo que proliferan las actividades informales, generalmente de baja productividad (Harris y Todaro, 1970). También se pueden tener efectos en sentido inverso cuando los costos económicos y sociales en las áreas receptoras son demasiado altos, ya sea porque se destinan muchos recursos públicos para atender necesidades relacionadas con obras urbanas y provisión de servicios básicos en nuevos asentamientos humanos o porque el aumento de personas desemplea- 
das o subempleadas estimula la delincuencia y un ambiente de inseguridad que inhibe la acumulación de capital. En lo que respecta a las zonas expulsoras, éstas se benefician por las razones contrarias, al liberarse de presiones sociales, laborales y sobre el gasto público. Se puede agregar que la migración impacta en el crecimiento económico de manera indirecta, a través de sus efectos en la dinámica demográfica.

\section{TIPOLOGÍA EN LOS PATRONES DE CRECIMIENTO}

\section{Aspectos conceptuales}

Un método para analizar las diferencias en tasas de crecimiento es recurrir a la descomposición del PIB per cápita y a la identificación de los factores que determinan la trayectoria de cada uno de sus componentes. De esta manera, se tiene que:

$$
Y / N=(Y / L)(L / N)
$$

en donde $Y$ es el PIB; $N$, la población, y $L$, el personal ocupado. Esta expresión se integra con dos componentes: el producto por trabajador $(Y / L)$, que es una medida indirecta de la productividad laboral, y la tasa de actividad económica $(L / N)$, que calcula el porcentaje de la población total que está integrada a las actividades laborales. ${ }^{2}$ Entre los factores que influyen en la evolución de la relación $L / N$, se pueden mencionar los cambios en la composición de la población por edades y sexos, en el grado de incorporación de las mujeres y los menores de edad al mercado de trabajo, en las costumbres y tradiciones populares que inciden en los índices de natalidad y en el rol social de la mujer, etcétera. Entre los factores que determinan la trayectoria de $Y / L$ destacan aquellos que afectan el incentivo para invertir y la transmisión del progreso técnico, tales como el dinamismo de la actividad económica, las tasas de inversión en capital físico y humano, los patrones de especialización en la producción, el grado de apertura comercial, la dotación de recursos e infraestructura básica, el respeto a la ley, la seguridad pública, la protección a los derechos de propiedad, etcétera (Ros, 2004).

La tasa de crecimiento del PIB per cápita $\left(g_{y}\right)$ se puede expresar en términos de los componentes de $Y / N$ como:

\footnotetext{
${ }^{2} L / N$ es también el inverso de la tasa de dependencia $(N / L)$.
} 


$$
g_{y}=g_{p}+g_{a}
$$

lo cual implica que ésta se explica por la suma de las tasas de crecimiento del producto por trabajador $\left(g_{p}\right)$ y la tasa de actividad económica $\left(g_{a}\right)$. Esto define tres posibilidades: que el crecimiento sea dirigido por incrementos en la productividad del trabajo; que lo sea por aumentos en el empleo al cambiar favorablemente la relación $L / N$, o bien, por una combinación de ambas situaciones. Alternativamente, considerando que

$$
Y=(Y / L)(L)
$$

la tasa de crecimiento del PIB agregado se puede plantear como

$$
g_{Y}=g_{p}+g_{L}
$$

lo que significa que la trayectoria de la producción es determinada por el dinamismo de la productividad y/o el empleo. Así, es posible definir cuatro áreas en el espacio $\left(g_{L}, g_{p}\right)$, cada una asociada con un tipo diferente de crecimiento (cuadro 1). El tipo 1, caracterizado por un rápido incremento de la productividad y la ocupación, corresponde al caso deseable que conduce rápidamente a una ruta de desarrollo, con una redistribución progresiva del ingreso debida a la expansión del empleo en un contexto de mejoras en la productividad del trabajo que permiten la elevación de los salarios reales.

El tipo 2, que implica un aumento acelerado de la productividad con un bajo dinamismo del empleo, coloca a la economía en una ruta de rápido crecimiento que, dependiendo de las condiciones demográficas, puede o no conducir a una reducción de la desigualdad y la pobreza. Esto es así porque el desplazamiento de puestos de trabajo debido al aumento de la productividad genera desempleo que se agrava si paralelamente se está incrementando la población económicamente activa. El resultado en este caso es una caída de los salarios reales que va acompañada de una mayor desocupación y subocupación, situación que eventualmente, si el proceso de crecimiento se sostiene, tiende a revertirse en el largo plazo. Si, por el contrario, se tratase de una economía con pleno empleo o cercano a éste, este tipo de crecimiento estaría reflejando la escasez de recursos humanos y de incentivos a las empresas para ampliar sus beneficios a través de mejoras en las prácticas productivas.

El tipo 3 ilustra una situación poco deseable para una economía en desarrollo, pues se trata de una condición en que tanto la productividad como la ocu- 
pación crecen lentamente, con lo que se profundiza el atraso económico. No obstante, podría también corresponder al caso de una economía desarrollada situada en un equilibrio de estado estacionario y creciendo a la tasa de progreso técnico.

\section{Cuadro 1. Tipos de crecimiento}

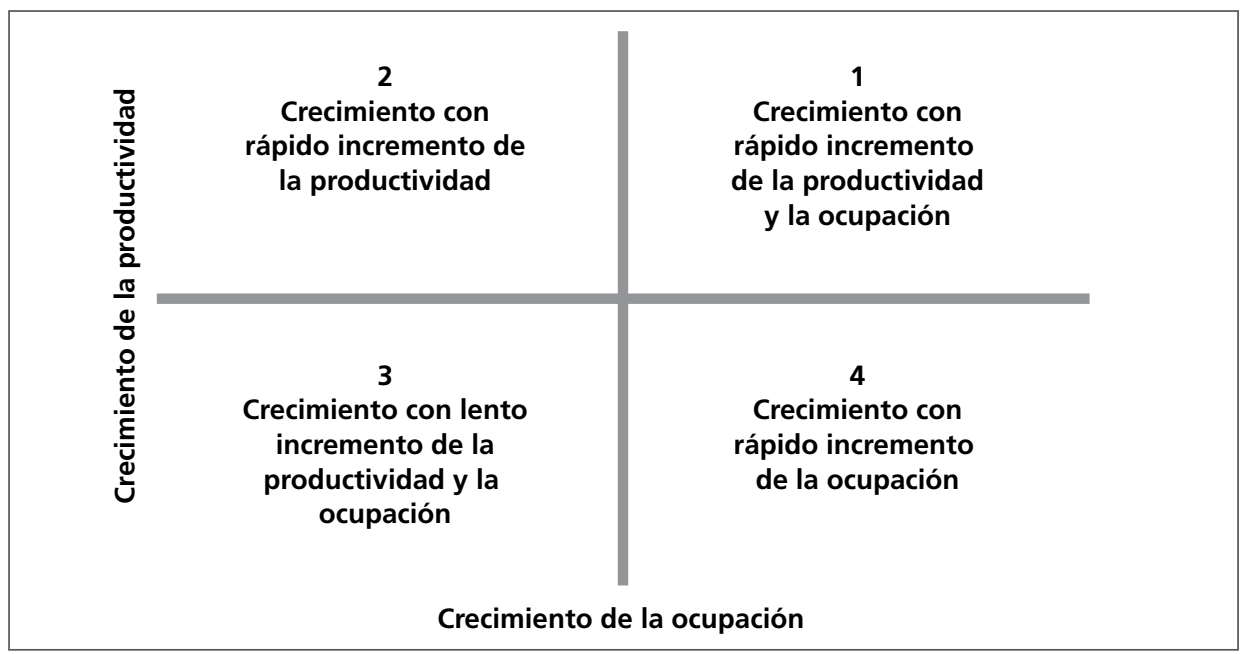

Por su parte, el tipo 4 ilustra un caso en que la productividad avanza con lentitud, pero la ocupación aumenta a tasas elevadas, lo cual sugiere que tienden a reproducirse empleos con niveles de productividad similar o inferior a los preexistentes. Si estos niveles ya son altos, como sucede en un país desarrollado, ubicarse en esta región no debiera ser motivo de preocupación; sin embargo, en un país de ingresos bajos o medios, en donde los niveles de productividad alcanzados son aún reducidos, este tipo de crecimiento podría retardar el proceso de desarrollo prolongando por mucho tiempo la etapa de bajos salarios.

Una dificultad para la aplicación empírica del análisis anterior es que se requiere establecer un punto de referencia para considerar si el crecimiento es alto o bajo, es decir, las líneas que delimitan las cuatro zonas del cuadro 1 . Si bien los promedios pueden ayudar a identificar este punto, tienen el inconveniente de que no proporcionan un referente único, sino que éste depende del grupo de economías que se tomen en cuenta para el cálculo. No obstante, si la selección del grupo es acorde con los fines analíticos que se persiguen, esta opción puede ser útil siempre que se contextualicen las inferencias realizadas. 


\section{Evidencia en la frontera norte}

La frontera norte es una de las regiones más beneficiadas con el proceso de apertura de la economía mexicana, lo cual se refleja en su tasa de crecimiento que para el periodo 1993-2010 supera significativamente a la media nacional, 1.5\% contra $1.1 \%$ considerando el PIB per cápita. Pero cuando se comparan las tasas por entidad federativa se aprecia un comportamiento heterogéneo que muestra a Chihuahua, Nuevo León, Sonora y Tamaulipas con valores muy cercanos entre sí y alrededor del promedio, mientras que Coahuila y Baja California registran valores extremos. La primera no sólo es la entidad económicamente más dinámica de la región, sino también una de las que mejor desempeño tuvieron a nivel nacional en el periodo de estudio, mientras que la segunda es la menos dinámica en la zona y la número 29 entre los estados del país (cuadro 2).

Cuadro 2. PIB per cápita por componentes

(pesos de 1993)

\begin{tabular}{|c|c|c|c|c|c|c|c|c|c|}
\hline & \multicolumn{2}{|c|}{$\begin{array}{l}\text { PIB per } \\
\text { cápita }\end{array}$} & \multirow{2}{*}{$\begin{array}{c}\begin{array}{c}\text { TCA } \\
(\%)\end{array} \\
1993-2010\end{array}$} & \multicolumn{2}{|c|}{$\begin{array}{l}\text { PIB por } \\
\text { trabajador }\end{array}$} & \multirow{2}{*}{$\begin{array}{c}\begin{array}{c}\text { TCA } \\
(\%)\end{array} \\
1993-2010\end{array}$} & \multicolumn{2}{|c|}{$\begin{array}{l}\text { Población } \\
\text { ocupada/ } \\
\text { Población }\end{array}$} & \multirow{2}{*}{$\begin{array}{c}\begin{array}{c}\text { TCA } \\
(\%)\end{array} \\
1993-2010\end{array}$} \\
\hline & 1993 & 2010 & & 1993 & 2010 & & 1993 & 2010 & \\
\hline Baja California & 17137 & 17930 & 0.3 & 45962 & 39943 & -0.8 & 0.373 & 0.449 & 1.1 \\
\hline Coahuila & 15961 & 23284 & 2.2 & 45451 & 56505 & 1.3 & 0.351 & 0.412 & 0.9 \\
\hline Chihuahua & 16734 & 21515 & 1.5 & 47831 & 53240 & 0.6 & 0.350 & 0.404 & 0.9 \\
\hline Nuevo León & 21748 & 28407 & 1.6 & 59774 & 62185 & 0.2 & 0.364 & 0.457 & 1.3 \\
\hline Sonora & 15113 & 19472 & 1.5 & 42273 & 48366 & 0.8 & 0.358 & 0.403 & 0.7 \\
\hline Tamaulipas & 13044 & 16806 & 1.5 & 37234 & 38981 & 0.3 & 0.350 & 0.431 & 1.2 \\
\hline Promedio regional & 16623 & 21236 & 1.5 & 46421 & 49870 & 0.4 & 0.358 & 0.426 & 1.0 \\
\hline Promedio nacional & 13015 & 15634 & 1.1 & 37911 & 37637 & 0.0 & 0.343 & 0.415 & 1.1 \\
\hline
\end{tabular}

Fuente: Elaboración propia con datos de INEGI (s.f.a; s.f.c).

Si se descompone el crecimiento del PIB per cápita tomando como referencia la ecuación (2), se aprecia que la principal fuente de crecimiento se encuentra en la tasa de actividad económica y no en la productividad del trabajo, como correspondería a una economía que se encuentra en una trayectoria de de- 
sarrollo y en la cual la generación de riqueza se acompaña con una distribución de ésta más equitativa. La región registra valores por debajo de la media del país en el primer indicador, $1 \%$ contra $1.1 \%$, y por encima de ésta en el segundo, $0.4 \%$ contra $0 \%$. Esto sugiere un crecimiento económico que, además de ser más acelerado, tiene mayores posibilidades de difundir beneficios sociales.

Si se analiza lo ocurrido en cada estado, se puede observar lo siguiente: en Baja California hay un estancamiento en el producto por trabajador y un acelerado incremento demográfico, que si bien fueron acompañados por un rápido aumento en el empleo, éste parece haberse orientado en gran proporción hacia sectores y actividades de baja productividad. El desempeño sobresaliente de Coahuila se asocia claramente con un fuerte dinamismo en la productividad del trabajo y una relativamente lenta expansión poblacional, lo que permitió su buen posicionamiento aun con un moderado incremento en el empleo. En Chihuahua, el aumento en el producto por trabajador es significativamente menor, poco menos de la mitad que el de Coahuila, mientras que su comportamiento demográfico y laboral es muy similar. Nuevo León y Tamaulipas observan poco crecimiento en la productividad laboral con movimientos favorables en la tasa de actividad económica, que en el primer caso se relaciona más con una rápida expansión de la ocupación y, en el segundo, con un menor dinamismo demográfico. Sonora corresponde a un caso en que el producto por trabajador evolucionó favorablemente, pero la relación entre población ocupada y población total avanzó con lentitud.

De acuerdo con la ecuación (4) y tomando como referencia los promedios nacionales, se pueden clasificar las seis entidades fronterizas por sus tipos de crecimiento de acuerdo con el cuadro 1, quedando como sigue: Nuevo León y Tamaulipas se localizan en el cuadrante 1, en el cual se tiene la mejor combinación entre crecimiento de la productividad y de la ocupación; Coahuila, Chihuahua y Sonora se ubican en el cuadrante 2, en donde el indicador de productividad es sobresaliente, pero no el de ocupación, mientras que Baja California se localiza en el 4 , en el que se tiene un rápido incremento del empleo con deterioro en el producto por trabajador (gráfica 1).

El análisis anterior plantea la siguiente interrogante: ¿Qué factores explican las diferencias en el comportamiento de la ocupación y la productividad entre las entidades fronterizas y de éstas con respecto al resto de los estados del país? La respuesta a esta pregunta requiere un examen detallado de la evolución de dichos indicadores y sus determinantes, lo cual es tema de los siguientes apartados. 
Gráfica 1. Tipos de crecimiento en los estados de México (1993-2010)

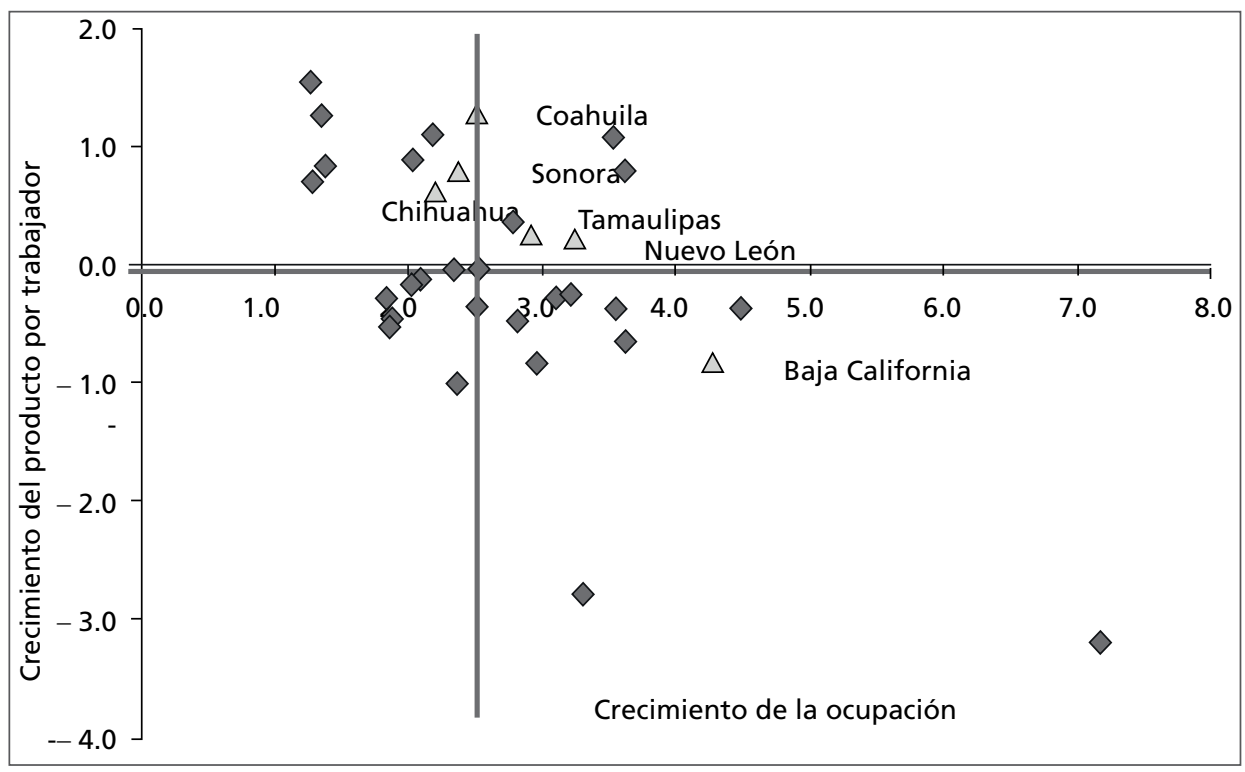

Fuente: INEGI (s.f.a).

\section{ANÁLISIS DE INDICADORES RELEVANTES}

\section{Cambios demográficos}

A partir de los noventa se conjugan en México dos fenómenos demográficos que modifican las condiciones para el crecimiento económico en el mediano plazo: por un lado, ocurre un cambio en la composición de la población por grupos de edad, que aumenta significativamente la población económicamente activa (PEA) elevando las presiones sobre el mercado laboral; por otro, el país transita hacia una menor tasa de incremento demográfico, ${ }^{3}$ lo que aunado a lo anterior permite reducir las tasas de dependencia económica de la población (gráfica 2). La conjunción de ambos fenómenos plantea retos y oportunidades que desafortunadamente no han sido aprovechados para un mayor crecimiento económico. Un aumento de la PEA en un contexto de desaceleración demográfica implica que una proporción mayor de la población se integra a las actividades laborales, lo que

\footnotetext{
${ }^{3}$ De 1960 a 1980, la tasa anual de crecimiento de la población fue de $3.3 \%$; de 1980 a 1990 , de $2 \%$; de 1990 a 2000, de $1.9 \%$, y de 2000 a 2010 de $1.3 \%$, de acuerdo con cálculos propios realizados con información de INEGI (s.f.b) para 1970, 1980, 1990, 2000 y 2010.
} 
por sí mismo debiera dinamizar la producción. La tasa de crecimiento del PIB per cápita se acelerará sólo si los nuevos miembros de la PEA se emplean en actividades de mediana y alta productividad; de lo contrario, el impacto será positivo sobre el PIB, pero mínimo o nulo sobre el producto por trabajador, lo cual mantendrá estancados los salarios reales y reducirá los niveles de bienestar.

Gráfica 2. Evolución de la PEA en México (1940-2010)

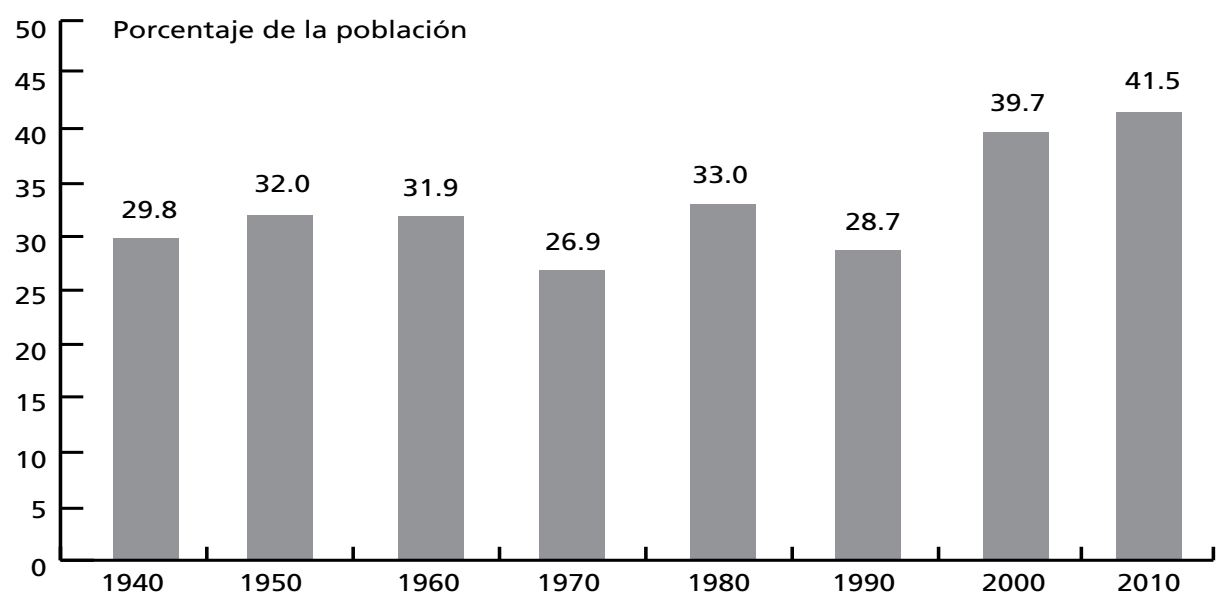

Fuente: Elaboración propia con información de INEGI (s.f.b) para varios años.

Dicha tendencia que afectó al país se reprodujo en los estados de la frontera norte, en donde la expansión demográfica fue más acelerada: $1.8 \%$ contra $1.4 \%$ anual entre 1993 y 2010. Este fenómeno debió ejercer un impacto negativo sobre el crecimiento económico de la región, aunque las cifras disponibles hacen suponer que en la mayoría de las entidades operaron otras fuerzas compensatorias que impulsaron a sus economías en sentido contrario. Al desagregar la tasa de crecimiento del PIB per cápita en sus componentes de tasa de crecimiento del producto y tasa de crecimiento de la población, se observa que en ambos indicadores los estados de la frontera norte superan a la media nacional: el PIB regional creció al 3.3\% anual y a un ritmo muy similar en cada una de las seis entidades, situándose entre $2.9 \%$ (Chihuahua) y $3.8 \%$ (Coahuila). En relación a la dinámica demográfica, se tiene que la población aumentó a tasas muy similares en cinco de los estados estudiados, con la excepción de Baja California, que registró una tasa de $3.1 \%$ anual, muy superior a las del resto y sólo superada a nivel nacional por la de Quintana Roo (cuadro 3). 
Cuadro 3. Tasas de crecimiento de indicadores económicos seleccionados (1993-2010)

\begin{tabular}{lcccc}
\hline & $\begin{array}{l}\text { PIB per } \\
\text { cápita }\end{array}$ & PIB & Población & PEA \\
\hline Baja California & 0.3 & 3.3 & 3.1 & 4.2 \\
\hline Coahuila & 2.2 & 3.8 & 1.6 & 2.5 \\
\hline Chihuahua & 1.5 & 2.9 & 1.4 & 2.2 \\
\hline Nuevo León & 1.6 & 3.5 & 1.9 & 3.2 \\
\hline Sonora & 1.5 & 3.2 & 1.7 & 2.4 \\
\hline Tamaulipas & 1.5 & 3.2 & 1.7 & 2.9 \\
\hline Promedio regional & $\mathbf{1 . 5}$ & $\mathbf{3 . 3}$ & $\mathbf{1 . 8}$ & $\mathbf{2 . 9}$ \\
\hline Promedio nacional & $\mathbf{1 . 1}$ & $\mathbf{2 . 5}$ & $\mathbf{1 . 4}$ & $\mathbf{2 . 5}$ \\
\hline
\end{tabular}

Fuente: Elaboración propia con datos de INEGI (s.f.a; s.f.b).

Es importante considerar que el impacto negativo del aumento demográfico en el crecimiento económico puede verse compensado si la composición de la población por grupos de edad se modifica favorablemente para elevar la tasa de actividad de la economía, pues ello implica un aumento en el porcentaje de personas que trabajan. No obstante, si las oportunidades de empleo se abren en sectores de baja productividad o los nuevos miembros de la PEA pasan a engrosar las filas de la subocupación y la desocupación, el efecto podría no ser tan positivo. En este caso, una agravante adicional se relaciona con la caída de los salarios reales que se deriva del exceso de mano de obra disponible. Las cifras de las tasas de crecimiento de la PEA confirman que ésta aumentó más rápidamente que la población, no sólo en la frontera norte, sino también en el resto del país, aunque una vez más el promedio fronterizo supera al nacional. La pregunta a responder es: ¿En qué sectores y tipos de actividad económica se ocuparon los miembros de la PEA que ingresaron al mercado de trabajo en el periodo de estudio? La respuesta a esta interrogante contiene información muy importante para comprender la trayectoria que siguió la economía mexicana en los últimos 20 años.

Un aspecto relevante en el análisis económico de la frontera norte es, sin duda, el fenómeno migratorio, el cual, aunque responde a las expectativas de la gente con respecto a las oportunidades favorables que ofrece esta zona, genera una serie de desequilibrios que podrían estar detrás de una trayectoria de lento crecimiento. Esto es así no sólo por su contribución al aumento poblacional, sino también porque eleva exponencialmente la demanda de servicios públicos, dete- 
riorando la calidad de éstos; presiona desfavorablemente al mercado laboral, provocando la caída de los salarios y la proliferación de actividades de subsistencia, y eleva los niveles de pobreza en las áreas receptoras, toda vez que la composición social de los flujos migratorios suele provenir de los estratos socioeconómicos más desfavorecidos.

Los datos disponibles muestran que Baja California es la única entidad de la frontera norte con una tasa de migración neta positiva: $1.2 \%$ como promedio anual en el periodo 1990-2010. En el resto de la región, las tasas observadas son negativas, aunque cercanas a cero en los casos de Nuevo León y Tamaulipas (cuadro 4). Esto contribuye a explicar las distintas trayectorias que siguió el PIB per cápita de las entidades de la región, sobre todo porque dio lugar a diferentes combinaciones entre aumentos de la PEA y la expansión poblacional, teniendo como resultado un menor o mayor dinamismo en la tasa de actividad económica, lo que condicionó la de crecimiento.

Si bien los aspectos demográficos ofrecen algunos elementos de análisis para comprender los diferenciales de desempeño económico entre los estados fronterizos norteños, los datos presentados en el cuadro 2 sugieren que gran parte de la explicación se debe buscar en el comportamiento del producto por trabajador, cuyos determinantes se asocian con la dinámica de la inversión, tanto en capital físico como en recursos humanos, con los procesos de especialización económica que determinan cómo se asignan sectorialmente los recursos disponibles y con factores institucionales que favorecen o entorpecen los procesos de innovación y adopción del progreso técnico. En los siguientes apartados se analizan las diferencias observables en las tasas de acumulación de capital físico y humano así como en los procesos de especialización.

Cuadro 4. Tasa de migración neta (1990-2010) (promedios del periodo)

\begin{tabular}{cc}
\hline & $\begin{array}{c}\text { Migración neta/ } \\
\text { Población }\end{array}$ \\
\hline Baja California & $1.19 \%$ \\
\hline Chihuahua & $-0.39 \%$ \\
\hline Coahuila & $-0.52 \%$ \\
\hline Nuevo León & $-0.01 \%$ \\
\hline Sonora & $-0.33 \%$ \\
\hline Tamaulipas & $-0.09 \%$ \\
\hline
\end{tabular}

Fuente: CONAPO (s.f). 


\section{Diferencias en la formación de capital físico y humano}

Una de las hipótesis para explicar el lento crecimiento de la economía mexicana en las últimas dos décadas propone como factor principal la caída de la inversión que resultó de la fuerte contracción del gasto gubernamental, sobre todo el destinado a ampliar y reponer infraestructura. El argumento señala que la inversión privada ha sido insuficiente para compensar dicha caída, con lo que se ha reducido el peso de esta variable dentro del PIB. En el periodo 1979-1981, la tasa de inversión fue de $24.9 \%$, compuesta por $13.9 \%$ de origen privado y $11 \%$ de procedencia pública, mientras que en 2006-2008 las cifras fueron $22.3 \%, 17.6 \%$ y 4.7\%, respectivamente (Moreno-Brid y Ros, 2009).

Cuadro 5. Componentes seleccionados de la inversión (porcentaje del PIB)

\begin{tabular}{lcccccc}
\hline & \multicolumn{3}{c}{ Inversión pública } & \multicolumn{2}{c}{ Inversión extranjera directa } \\
\hline & 1993 & 2010 & $\begin{array}{c}\text { Promedio } \\
1993-2010\end{array}$ & 1994 & 2010 & $\begin{array}{c}\text { Promedio } \\
1994-2010\end{array}$ \\
\hline Baja California & 2.67 & 3.03 & 2.29 & 2.73 & 3.77 & 5.39 \\
\hline Coahuila & 1.71 & 7.87 & 2.91 & 1.24 & 0.30 & 1.41 \\
\hline Chihuahua & 1.78 & 2.68 & 2.43 & 2.83 & 6.21 & 4.80 \\
\hline Nuevo León & 2.43 & 2.56 & 1.95 & 5.02 & 8.72 & 5.70 \\
\hline Sonora & 4.73 & 4.48 & 3.53 & 1.41 & 0.59 & 2.09 \\
\hline Tamaulipas & 4.92 & 16.98 & 6.61 & 4.43 & 0.93 & 2.81 \\
\hline Frontera norte & 3.04 & 6.27 & 3.29 & 2.95 & 3.42 & 3.70 \\
\hline
\end{tabular}

Fuente: Presidencia de la República (s.f.a; s.f.b), para varios años; INEGI (s.f.a).

La evaluación de esta hipótesis en el ámbito regional o por entidad federativa plantea problemas difíciles de salvar debido a que no existen datos oficiales disponibles sobre dicha variable con este nivel de desagregación. No obstante, es posible lograr una aproximación con la inversión pública (federal, estatal y municipal) en infraestructura y la inversión extranjera directa, las cuales se pueden consultar en los informes de la Presidencia de la República (s.f.a; s.f.b) y en el Banco de Información Económica del Instituto Nacional de Estadística y Geografía (INEGI, s.f.a). Las cifras disponibles muestran que, con la excepción de Sonora, en el resto de las entidades de la región la inversión pública en infraestructura como porcentaje del PIB tiende a aumentar; lo mismo ocurre con la inversión extranjera directa en Baja California, Chihuahua y Nuevo León, y lo contrario en Coahuila, Sonora y Tamaulipas. Los promedios del periodo arrojan diferencias 
entre los estados que no se corresponden con aquéllas observadas en las tasas de crecimiento, lo cual podría interpretarse en el sentido de que esta variable contribuye poco a explicar por qué difieren los desempeños en las seis entidades (cuadro 5).Sin embargo, se debe señalar que en este cálculo se deja de lado la trayectoria seguida por dicha variable año tras año, omitiéndose información relevante. Más adelante se subsana esta deficiencia a través de un ejercicio econométrico con datos de panel que toma en cuenta las variaciones anuales en la inversión por trabajador. Asimismo, es importante aclarar que otra limitación de este ejercicio es que no considera los montos invertidos por el sector privado nacional por no existir en las bases de datos oficiales información confiable y comparable para distintos periodos.

La teoría enseña que el desarrollo económico es influido no sólo por la inversión en capital físico e infraestructura, sino también por la formación de capital humano, la cual suele medirse a través de la escolaridad de la población que realiza actividades laborales y por las tasas de cobertura alcanzadas en distintos niveles educativos, frecuentemente en la educación secundaria. El primero de estos indicadores se utiliza para medir indirectamente el capital humano acumulado por trabajador, mientras que el segundo se emplea como medición indirecta de las tasas de la inversión que realiza la sociedad en la producción de este factor. Con respecto a la escolaridad de la PEA se tiene que ésta supera al promedio nacional en las seis entidades, destacando Nuevo León y Coahuila como las de nivel más alto. Si se comparan las tasas de crecimiento anuales de dicho indicador entre 1990 y 2010 , se observa que éstas son muy similares en toda la región, prácticamente iguales en cuatro entidades (1.3\%) y sólo ligeramente inferiores en las otras dos $(1 \%)$, aunque en ambos casos son inferiores a la registrada nacionalmente (cuadro 6).

Cuadro 6. Escolaridad de la población económicamente activa

\begin{tabular}{|c|c|c|c|}
\hline \multirow[t]{2}{*}{ Entidades } & \multicolumn{3}{|c|}{$\begin{array}{l}\text { Años promedio de } \\
\text { asistencia a la escuela }\end{array}$} \\
\hline & 1990 & 2010 & TCA \\
\hline Baja California & 7.5 & 9.3 & 1.0 \\
\hline Coahuila & 7.3 & 9.5 & 1.3 \\
\hline Chihuahua & 6.8 & 8.8 & 1.3 \\
\hline Nuevo León & 8.0 & 9.8 & 1.0 \\
\hline Sonora & 7.3 & 9.4 & 1.3 \\
\hline Tamaulipas & 7.0 & 9.1 & 1.3 \\
\hline Frontera norte & 7.3 & 9.3 & 1.2 \\
\hline Nacional & 6.5 & 8.6 & 1.5 \\
\hline
\end{tabular}

Fuente: INEGI (s.f.b), para 1990 y 2010. 
En lo que se refiere a las tasas de cobertura, la información disponible sugiere una tendencia hacia la igualación en la educación secundaria, que si bien evoluciona a tasas distintas se debe al rezago preexistente en estados como Chihuahua y Tamaulipas. Algo parecido ha ocurrido en la educación media superior, aunque en este caso Sonora tiende a despegarse del resto de la región alcanzando en 2010 una tasa de $72.7 \%$, que es, por ejemplo, diez puntos porcentuales superior a la de Nuevo León (62.6\%) y Coahuila (62.8\%). En la educación superior la frontera norte supera a la media del país; únicamente Baja California se sitúa por debajo, aunque simultáneamente está entre las que mayores avances ha tenido en las últimas dos décadas, junto con Sonora y Chihuahua (cuadro 7).

\section{Cuadro 7. Tasas de cobertura por nivel educativo}

\begin{tabular}{lrrrrrrrrrr}
\hline \multicolumn{1}{c}{ Entidades } & \multicolumn{2}{c}{$\begin{array}{c}\text { Educación } \\
\text { secundaria }\end{array}$} & \multicolumn{3}{c}{$\begin{array}{c}\text { Educación } \\
\text { media superior }\end{array}$} & \multicolumn{3}{c}{$\begin{array}{c}\text { Educación } \\
\text { superior }\end{array}$} \\
& 1990 & 2010 & $\Delta \%$ & 1990 & 2010 & $\Delta \%$ & 1990 & 2010 & $\Delta \%$ \\
\hline Baja California & 74.6 & 96.8 & 29.8 & 39.5 & 63.8 & 61.5 & 11.8 & 26.3 & 122.9 \\
\hline Coahuila & 75.8 & 96.6 & 27.4 & 35.6 & 62.8 & 76.4 & 16.5 & 32.4 & 96.4 \\
\hline Chihuahua & 60.7 & 94.3 & 55.4 & 30.2 & 64.6 & 113.9 & 12.6 & 29.8 & 136.5 \\
\hline Nuevo León & 82.4 & 98.0 & 18.9 & 41.2 & 62.6 & 51.9 & 22.1 & 38.6 & 74.7 \\
\hline Sonora & 81.1 & 96.0 & 18.4 & 45.1 & 72.7 & 61.2 & 15.0 & 36.5 & 143.3 \\
\hline Tamaulipas & 71.8 & 94.3 & 31.3 & 35.0 & 65.6 & 87.4 & 20.4 & 34.4 & 68.6 \\
\hline Frontera norte & $\mathbf{7 4 . 4}$ & $\mathbf{9 6 . 0}$ & $\mathbf{2 9 . 0}$ & $\mathbf{3 7 . 8}$ & $\mathbf{6 5 . 4}$ & $\mathbf{7 3 . 0}$ & $\mathbf{1 6 . 4}$ & $\mathbf{3 3 . 0}$ & $\mathbf{1 0 1 . 2}$ \\
\hline Nacional & $\mathbf{5 3 . 3}$ & $\mathbf{9 7 . 1}$ & $\mathbf{8 2 . 2}$ & $\mathbf{1 8 . 0}$ & $\mathbf{6 5 . 6}$ & $\mathbf{2 6 4 . 4}$ & $\mathbf{8 . 3}$ & $\mathbf{2 7 . 0}$ & $\mathbf{2 2 5 . 3}$ \\
\hline
\end{tabular}

Fuente: INEGI (s.f.b), para 1990 y 2010; SEP (s.f).

Un aspecto que dejan claro estos datos es que el lento crecimiento de la productividad que caracteriza a la región y al país, no obedece ni a una lenta formación de capital humano, ni a una escasez en la disponibilidad de este recurso. Por el contrario, las tasas a las que se ha generado capital humano adicional son altas y, en todo caso, estarían reflejando ausencia de capacidades productivas para utilizarlo eficientemente, quizá por las dificultades para abrir fuentes de empleo en sectores intensivos en el uso de este factor. De la misma manera, las diferencias observadas entre las seis entidades no parecen ser un elemento de peso para explicar sus desiguales desempeños económicos. 


\section{El rol de la especialización}

Una hipótesis que se puede plantear es que la desaceleración en el crecimiento del producto por trabajador obedece a una pérdida de peso relativo, dentro del empleo estatal, de aquellos sectores y actividades más dinámicas y con mayor capacidad de arrastre sobre el conjunto de la economía, como lo es la industria manufacturera, teniendo como contraparte una expansión de las actividades de servicios tradicionales y de la informalidad, así como de la subocupación y la desocupación. Según esta idea, el rápido aumento de la PEA ocurrido a partir de los noventa en un contexto de estancamiento de la inversión implicó que la nueva mano de obra disponible no encontrara espacios laborales en el sector formal de la economía, por lo que se orientó hacia actividades informales. Si bien esta hipótesis, al igual que la anterior, podría validarse para el país en su conjunto, falta corroborar si proporciona información relevante para entender las particularidades de cada estado dentro de la región. En otras palabras: ¿El buen desempeño de Coahuila, el lento crecimiento de Baja California y el comportamiento promedio de Chihuahua, Nuevo León, Sonora y Tamaulipas se explican por las distintas tendencias sectoriales del empleo?

\section{Cuadro 8. Distribución sectorial del personal ocupado (porcentajes)}

\begin{tabular}{|c|c|c|c|c|c|c|c|c|c|c|c|c|}
\hline & \multicolumn{3}{|c|}{ Primario } & \multicolumn{3}{|c|}{$\begin{array}{c}\text { Secundario } \\
\text { sin manufacturas }\end{array}$} & \multicolumn{3}{|c|}{ Manufacturas } & \multicolumn{3}{|c|}{ Terciario } \\
\hline & 1996 & 2010 & TCA* & 1996 & 2010 & TCA* & 1996 & 2010 & TCA* & 1996 & 2010 & TCA* \\
\hline Baja California & 8.0 & 6.3 & 1.5 & 8.6 & 8.5 & 3.1 & 22.8 & 19.5 & 2.0 & 60.6 & 65.7 & 3.8 \\
\hline Coahuila & 9.1 & 5.2 & -2.3 & 10.1 & 9.0 & 0.8 & 26.2 & 22.3 & 0.5 & 54.6 & 63.4 & 2.7 \\
\hline Chihuahua & 15.7 & 10.4 & -1.8 & 8.1 & 8.6 & 1.5 & 27.1 & 21.9 & -0.4 & 49.0 & 59.0 & 2.5 \\
\hline Nuevo León & 6.2 & 2.4 & -4.4 & 8.4 & 9.6 & 3.4 & 24.0 & 20.3 & 1.2 & 61.4 & 67.7 & 3.2 \\
\hline Sonora & 21.7 & 9.8 & -4.3 & 9.7 & 9.7 & 1.4 & 15.1 & 18.5 & 2.8 & 53.5 & 61.9 & 2.4 \\
\hline Tamaulipas & 12.4 & 6.7 & -2.5 & 8.7 & 11.3 & 3.7 & 18.2 & 18.7 & 2.0 & 60.6 & 63.3 & 2.2 \\
\hline Frontera norte & 12.2 & 6.8 & -2.3 & 9.0 & 9.5 & 2.5 & 22.2 & 20.2 & 1.4 & 56.6 & 63.5 & 2.8 \\
\hline Nacional & 22.2 & 13.3 & -1.8 & 7.6 & 8.6 & 2.8 & 16.7 & 15.5 & 1.4 & 53.7 & 62.6 & 3.0 \\
\hline
\end{tabular}

*Se refiere al crecimiento en el número de personas ocupadas no de los porcentajes. Fuente: INEGI (s.f.c). 
La información del cuadro 8 apoya la existencia de tres grandes tendencias que se perfilan en la región durante el periodo 1996-2010: 1) una contracción relativa del sector primario, que coincide con lo ocurrido en el plano nacional y que incluso se acompaña de una reducción de puestos de trabajo en términos absolutos, excepto en Baja California, donde éstos continúan expandiéndose a una tasa de $1.5 \%$ anual. 2) Una caída en la participación del sector manufacturero, que coincide con la tendencia nacional, pero que no es homogénea en la región, toda vez que Sonora y Tamaulipas se mueven en sentido contrario. 3) Un proceso de "terciarización" que avanza de manera firme a lo largo del país y a nivel regional y que se manifiesta con una acelerada expansión de la ocupación a tasas anuales de $3 \%$ y $2.8 \%$ respectivamente, destacando Baja California y Nuevo León, donde fueron de $3.8 \%$ y $3.2 \%$ por ciento.

El proceso de "terciarización" que ilustran estos datos podría explicar, por lo menos parcialmente, por qué se desaceleró el crecimiento de la productividad del trabajo, pues es sabido que las actividades terciarias suelen ser menos dinámicas que las manufactureras en cuanto a capacidad de innovación y para incorporar el progreso técnico, aunque ello depende de la composición por tipo de empleo (Rowthorn y Ramaswamy, 1997). Esto es así aun cuando algunos servicios profesionales, financieros y de comunicaciones son intensivos en tecnología y capital humano, debido a que este sector concentra también muchas actividades de baja productividad, como las informales y las tareas agrupadas en el sector del hogar.

La distribución del personal empleado en los sectores formal e informal muestra que este último ha avanzado en términos de su participación dentro de la ocupación total en cinco de las seis entidades fronterizas, sin contar a Tamaulipas. Esto implica que en dicho grupo el empleo en las actividades informales creció más rápido que en las formales, en especial en Baja California y Nuevo León con tasas de crecimiento de $3.3 \%$ y $2.7 \%$ anual, respectivamente. Si el análisis se realiza tomando en cuenta al sector del hogar, las cifras muestran una tendencia distinta, pues la participación relativa de este sector cae en cuatro entidades, excepto Sonora y Coahuila. Al considerar las tasas a las que crece la ocupación en este sector, las de Baja California y Nuevo León se mantienen otra vez como las más altas (cuadro 9). Este segmento ocupacional agrupa explotación de pequeñas parcelas ejidales, producción artesanal, comercio minorista, ambulantaje, transporte de carga y taxis, así como reparaciones diversas, servicios domésticos y servicios sexuales, entre otras actividades, muchas de las cuales pueden realizarse dentro de la informalidad y otras de manera formal, pero cuya 
característica principal es su reducido o nulo uso de capital y la obtención de beneficios rápidos.

Cuadro 9. Distribución del personal ocupado entre los sectores formal e informal

\begin{tabular}{lccccccccr}
\hline & \multicolumn{3}{c}{$\begin{array}{c}\text { Sector formal } \\
\text { (Porcentaje del PO) }\end{array}$} & \multicolumn{3}{c}{$\begin{array}{c}\text { Sector del hogar } \\
\text { (Porcentaje del PO) }\end{array}$} & \multicolumn{3}{c}{$\begin{array}{c}\text { Sector Informal } \\
\text { (Porcentaje del PO) }\end{array}$} \\
\hline & 1996 & 2010 & TCA $^{*}$ & 1996 & 2010 & TCA $^{*}$ & 1996 & 2010 & TCA $^{*}$ \\
\hline Baja California & 79.7 & 79.3 & 3.2 & 23.6 & 23.2 & 3.1 & 20.3 & 20.7 & 3.3 \\
\hline Coahuila & 76.9 & 74.5 & 1.4 & 29.4 & 30.3 & 1.8 & 23.1 & 25.5 & 2.4 \\
\hline Chihuahua & 80.4 & 79.6 & 1.0 & 26.4 & 24.1 & 0.4 & 19.6 & 20.4 & 1.4 \\
\hline Nuevo León & 77.1 & 76.1 & 2.4 & 30.2 & 28.5 & 2.0 & 22.9 & 23.9 & 2.7 \\
\hline Sonora & 77.7 & 75.5 & 1.1 & 25.9 & 28.0 & 1.9 & 22.3 & 24.5 & 2.0 \\
\hline Tamaulipas & 75.0 & 75.1 & 1.9 & 33.4 & 30.3 & 1.1 & 25.0 & 24.9 & 1.8 \\
\hline Frontera norte & $\mathbf{7 7 . 8}$ & $\mathbf{7 6 . 7}$ & $\mathbf{1 . 8}$ & $\mathbf{2 8 . 2}$ & $\mathbf{2 7 . 4}$ & $\mathbf{1 . 7}$ & $\mathbf{2 2 . 2}$ & $\mathbf{2 3 . 3}$ & $\mathbf{2 . 3}$ \\
\hline Nacional & $\mathbf{7 3 . 4}$ & $\mathbf{7 1 . 7}$ & $\mathbf{1 . 7}$ & $\mathbf{3 8 . 1}$ & $\mathbf{3 6 . 4}$ & $\mathbf{1 . 5}$ & $\mathbf{2 6 . 6}$ & $\mathbf{2 8 . 3}$ & $\mathbf{2 . 3}$ \\
\hline
\end{tabular}

*Se refiere al crecimiento en el número de personas no de los porcentajes.

Fuente: INEGI (s.f.c).

Las cifras de este cuadro sugieren que el lento ritmo de crecimiento que se observa en el producto por trabajador en los últimos veinte años, se puede asociar con un proceso de "terciarización" caracterizado por un incremento en la importancia relativa de las actividades de baja productividad concentradas principalmente en el grupo ocupacional del hogar y en la informalidad. Esta tendencia, que se registra tanto en todo el país como en la región fronteriza, ha tenido un impacto sobresaliente en Baja California y Nuevo León, donde las actividades de este tipo se han multiplicado aceleradamente. Cabe señalar que si bien el fenómeno parece ser un factor explicativo relevante para comprender la experiencia de dichas entidades federativas, no parece aportar mucho para entender lo ocurrido en Coahuila y Sonora, donde la ocupación del sector creció más rápido que en las actividades formales sin que ello significase un freno al incremento de la productividad laboral.

Una hipótesis razonable para explicar esta situación es que las actividades de baja productividad o aquéllas donde se mantuvo estancada no se limitan a las de carácter informal o a las del sector del hogar, sino que se extienden a un segmento más amplio de labores. Asimismo, los niveles y ritmos a los que aumenta la productividad dentro de un sector pueden diferir entre entidades federativas debido a una composición diferenciada por tipo de actividad, por lo que 
aun con rasgos similares en las participaciones de los grandes sectores en el empleo, ello pudo dar lugar a desempeños económicos diferentes en cada región y entidad del país. La información que se presenta en el cuadro 10 es ilustrativa en este sentido y muestra que, efectivamente, los sectores no son homogéneos de un estado a otro. Por ejemplo, la productividad de las tareas agropecuarias es alta en Sonora, Nuevo León, Chihuahua y Coahuila, con relación al promedio regional, y baja en los otros dos estados, mientras que en comparación con el promedio nacional es alta en cinco estados y sólo Baja California es la excepción. Por otra parte, llaman la atención los elevados ritmos a los que aumenta el producto por trabajador, que en términos generales superan a los observados en otros sectores.

Una interpretación de estos hechos sugiere la existencia de distintos niveles de capitalización del campo en la región y el país, lo que, a su vez, obedecería al impacto diferenciado de las reformas al agro que se implementaron en los noventa y que permitieron la modernización agrícola en algunas zonas de la nación. Estas reformas se dejaron sentir principalmente a través de dos vías: promoviendo la tecnificación y eliminando el desempleo disfrazado.

Cuadro 10. Producto por trabajador en sectores de actividad económica por entidad federativa

\begin{tabular}{|c|c|c|c|c|c|c|c|c|c|c|c|c|}
\hline & \multicolumn{3}{|c|}{ Primario } & \multicolumn{3}{|c|}{$\begin{array}{c}\text { Secundario } \\
\text { sin manufacturas }\end{array}$} & \multicolumn{3}{|c|}{ Manufacturas } & \multicolumn{3}{|c|}{ Terciario } \\
\hline & 1996 & 2010 & TCA & 1996 & 2010 & TCA & 1996 & 2010 & TCA & 1996 & 2010 & TCA \\
\hline Baja California & 21717 & 17533 & -1.5 & 36929 & 27763 & -2.0 & 39815 & 41864 & 0.4 & 37264 & 39707 & 0.5 \\
\hline Coahuila & 21645 & 41165 & 4.7 & 41786 & 43609 & 0.3 & 64532 & 87452 & 2.2 & 34648 & 40738 & 1.2 \\
\hline Chihuahua & 23271 & 41498 & 4.2 & 29187 & 34749 & 1.3 & 38567 & 47352 & 1.5 & 48946 & 63802 & 1.9 \\
\hline Nuevo León & 16751 & 41804 & 6.8 & 31482 & 39390 & 1.6 & 61424 & 84068 & 2.3 & 46902 & 56424 & 1.3 \\
\hline Sonora & 27273 & 67011 & 6.6 & 34760 & 34544 & 0.0 & 49517 & 48359 & -0.2 & 36265 & 47717 & 2.0 \\
\hline Tamaulipas & 24336 & 33456 & 2.3 & 34345 & 39864 & 1.1 & 39388 & 51886 & 2.0 & 28672 & 34478 & 1.3 \\
\hline $\begin{array}{l}\text { Promedio } \\
\text { regional }\end{array}$ & 22499 & 40411 & 4.3 & 34748 & 36653 & 0.4 & 48877 & 60164 & 1.5 & 38783 & 47144 & 1.4 \\
\hline $\begin{array}{l}\text { Promedio } \\
\text { nacional }\end{array}$ & 10233 & 17081 & 3.7 & 34353 & 33160 & -0.3 & 42893 & 48526 & 0.9 & 34103 & 35411 & 0.3 \\
\hline
\end{tabular}

Fuente: Elaboración propia con datos de INEGI (s.f.a; s.f.b).

En las labores manufactureras y terciarias se observa una heterogeneidad muy semejante, en la que destacan por su elevada productividad Coahuila y 
Nuevo León, en las primeras, y Chihuahua y Nuevo León, en las segundas. Si lo que se mide es el dinamismo, las entidades con mejor desempeño en las manufacturas son Nuevo León, Coahuila y Tamaulipas, mientras que en los servicios sobresalen Sonora y Chihuahua. En ambos sectores, los niveles y tasas de crecimiento del producto por trabajador de la zona fronteriza superan al promedio nacional. El único grupo de actividades en donde se observa cierta homogeneidad regional y nacional en los niveles de productividad es en el secundario (excluyendo manufacturas), que aglutina minería, construcción, electricidad y agua.

El panorama que surge de este análisis es que el buen desempeño a nivel agregado en materia de productividad laboral se asocia estrechamente con logros en el sector terciario, en el que la expansión del empleo fue mayor; en las manufacturas, cuyo liderazgo en los procesos de desarrollo está ampliamente documentado, y en sectores con alta participación dentro de la ocupación estatal.

En cuanto al rol de las manufacturas, se debe hacer una precisión importante: en la experiencia de esta región la industria maquiladora ha sido con frecuencia el principal generador de empleo dentro del sector, situación que reduce los efectos positivos de la industrialización sobre el desarrollo. La razón es que este tipo de industria desplaza a la región sobre todo actividades de ensamble que demandan mano de obra de baja calificación y en las que el crecimiento de la productividad es lento, además de no impulsar la difusión tecnológica por sus bajos índices de integración con la economía local. De 1990 a 2010, se generaron en dicha industria 198341 puestos de trabajo en Nuevo León; 132 050, en Baja California; 120 926, en Coahuila; 81 013, en Chihuahua; 71 841, en Tamaulipas, y 54 663, en Sonora, obteniéndose en todos los casos tasas de crecimiento anual superiores a las del sector manufacturero en su conjunto (cuadro 11). El

Cuadro 11. Indicadores de la industria maquiladora

\begin{tabular}{lrccc}
\hline & \multicolumn{5}{c}{ Ocupación } & \\
\hline Baja California & 1990 & 2010 & $\begin{array}{c}\text { Variación absoluta } \\
1990-2010\end{array}$ & TCA \\
\hline Coahuila & 87709 & 219759 & 132050 & 4.7 \\
\hline Chihuahua & 30965 & 151891 & 120926 & 8.3 \\
\hline Nuevo León & 166749 & 247762 & 81013 & 2.0 \\
\hline Sonora & 14251 & 212592 & 198341 & 14.5 \\
\hline Tamaulipas & 38935 & 93598 & 54663 & 4.5 \\
\hline
\end{tabular}

Fuente: INEGI (s.f.a). 
dinamismo del empleo en la industria maquiladora y en las actividades terciarias, particularmente de aquéllas relacionadas con la informalidad y el sector del hogar, así como su elevado tamaño relativo, sugieren un rol importante en la explicación de las diferencias en la trayectoria del producto por trabajador.

\section{ANÁLISIS ECONOMÉTRICO}

\section{Aspectos metodológicos}

En este trabajo se estima un modelo econométrico (usando el programa Eviews) que se determinó siguiendo los argumentos teóricos presentados en párrafos anteriores y tomando como referencia una función producción del tipo $Y=F(K, H$, $A L$ ), en donde $Y$ se refiere al nivel del producto; $K$, a las existencias de capital físico; $H$ al acervo de capital humano, y $A L$, a las unidades de trabajo efectivo que capturan el efecto conjunto de la tecnología, $A$, y del trabajo, $L$, sobre la producción. Esta función se puede reexpresar en términos de unidades por trabajador como $y=F(k, h, A)$, que a su vez en tasas de crecimiento corresponde a $\Delta y / y$ $=F(\Delta A / A, \Delta k / k, \Delta h / h)$.

Se puede asumir que $\Delta A / A=\lambda_{0}+\chi+\varepsilon$, lo cual supone que las variaciones porcentuales de $A$ dependen de un componente fijo y exógeno, $\lambda 0$, más un vector de variables que directa o indirectamente la afectan, como pueden ser los procesos de especialización económica y la dinámica migratoria, entre otros, $\mathrm{y}$ que quedan capturados en $\chi$. Asimismo, se considera un término de error aleatorio, $\varepsilon$, que captura el impacto de otros eventos no contemplados que generan diferencias interestatales en $\triangle A / A$.

Uno de los problemas más frecuentes que se enfrentan en el trabajo empírico es que no siempre es posible disponer de bases de datos que correspondan con exactitud a las variables que se manejan en la teoría, lo cual en México es especialmente cierto cuando se trata de información por entidades federativas. El ejemplo más claro de esta situación es el de $k=K / L$, que se refiere a las existencias de capital físico por trabajador, toda vez que no existe una variable exacta en las cuentas nacionales y estatales para representar $K$. Ello hizo necesario su medición indirecta a través de la inversión pública total (IPT) ${ }^{4}$ lo que generó una segunda dificultad al omitirse la inversión privada, para la cual tampoco existe

\footnotetext{
${ }^{4}$ La IPT aglutina la inversión pública federal, estatal y municipal.
} 
información estatal con periodicidad anual..$^{5}$ No obstante, en la medida en que la relación entre inversión privada y tasa de crecimiento del PIB puede estar sujeta a doble causalidad, la IPT puede fungir como variable instrumental para eliminar posibles problemas de endogeneidad. Esto es correcto sobre todo si existe complementariedad entre ambos tipos de inversión y la de carácter público estimula a la de origen privado en lugar de desplazarla, lo cual es una cuestión empírica.

El capital humano por trabajador se representa con los años de escolaridad de la población económicamente activa (ESCOLAR_PEA), mientras que el efecto atribuible a las tendencias de especialización se captura mediante las tasas de crecimiento de la ocupación en los sectores primario (TCA_OCUP_PRIM), terciario (TCA_OCUP_TERC), del hogar (TCA_OCUP_HOGAR), en la industria manufacturera (TCA_OCUP_MANUF) y en la maquila (TCA_OCUP_MAQUILA). Por su parte, el impacto del fenómeno migratorio se introduce mediante la variable tasa de migración neta (TMN). Las equivalencias empleadas en el trabajo empírico para cada una de las variables que se derivan directamente de la teoría se presentan a continuación: ${ }^{6} \Delta y / y=$ TCA_PIB/PEA, $\Delta \mathrm{k} / \mathrm{k}=$ TCA_IPT $/ \mathrm{PEA}, \Delta h / h=$ TCA_ESCOLAR_PEA, $\chi_{1}=$ TCA_OCUP_PRIM, $\chi_{2 a}=$ TCA_OCUP_MANUF, $\chi_{2 b}=$ TCA_OCUP MAQUILA, $\chi_{3}=$ TCA_OCUP_TERC, $\chi_{4}=$ TCA_OCUP_HOGAR y $\chi_{5}=$ TMN. La información utilizada corresponde al periodo 1996-2010 para las seis entidades de la frontera norte y la fuente de información para la mayoría de las variables son el Banco de Información Económica (INEGI, s.f.a) y la Encuesta Nacional de Ocupación y Empleo del INEGI (s.f.c), excepto en los casos de la IPT, en que el componente federal se obtuvo de los informes de la Presidencia de la República (s.f.a; s.f.b), y de la TMN, que se consultó en la página web del Consejo Nacional de Población (CONAPO, s.f). Se estimó un modelo que toma como referencia la ecuación (5), pero se realizaron ajustes para incluir o excluir variables de acuerdo con su significación estadística o tratando de evitar problemas de multicolinealidad. También se utilizaron rezagos en algunas variables explicativas como variables instrumentales cuando se tuvo sospecha de posibles problemas de endogeneidad, o cuando ello permitió mejorar los estadísticos de evaluación del modelo.

\footnotetext{
${ }^{5}$ En las bases de datos de INEGI se puede obtener una serie de inversión extranjera directa cuyo principal inconveniente es que el registro se hace en la entidad federativa donde se encuentra la empresa matriz, no donde se realiza la inversión física. Esto genera una sobrestimación para el Distrito Federal y una subestimación para muchos estados.

${ }^{6}$ TCA se refiere a la tasa de crecimiento anual. La TMN se obtiene de restar la emigración a la inmigración y de ponderar entre el total de la población.
} 


$$
\begin{aligned}
& T C A \_P I B / P E A_{i t}=\alpha_{0}+\alpha_{1} T C A \_I P T / P E A_{i t}+\alpha_{2} T C A \_E S C O L A R \_P E A_{i t}+ \\
& \alpha_{3} \text { TCA_OCUP_PRIM }{ }_{i t}+\alpha_{4} \text { TCA_OCUP_MANUF } F_{i t}+ \\
& \alpha_{5} \text { TCA_OCUP_TERC } C_{i t}+\alpha_{6} \text { TCA_OCUP_HOGAR }{ }_{i t}+ \\
& \alpha_{7} T M N_{i t}+\varepsilon_{i t}
\end{aligned}
$$

En la ecuación (5) 7 , de acuerdo con la teoría, se espera que $\alpha_{1}, \alpha_{2}$ y $\alpha_{4}>$ 0 , mientras que $\alpha_{6}<0$. El signo de $\alpha_{3}$ depende del grado de modernización del agro, pudiendo ser negativo si predominan las prácticas tradicionales; no obstante, por las características de la región norte es razonable suponer que $\alpha_{3}>0$. En el caso de $\alpha_{5}$, su signo es determinado por la composición del sector terciario entre actividades de alta y baja productividad; puesto que uno de los argumentos que se desarrollan en este documento es que la expansión del empleo dentro de los servicios se orientó principalmente hacia las actividades informales y del hogar, la expectativa es que $\alpha_{5}<0$. Con respecto a $\alpha_{7}$, su signo estará condicionado por el tipo de efectos que predominan: si las corrientes migratorias transfieren suficiente capital humano para convertirse en una fuente de atracción de nuevas inversiones en las zonas receptoras, su valor será positivo. Si implican grupos sociales con baja escolaridad, que generan elevados costos económicos y sociales relacionados con el gasto público que se destina a atender sus necesidades y provocan una proliferación de la informalidad y los empleos de baja productividad, su valor será negativo. De acuerdo con la hipótesis de este trabajo se esperaría que $\alpha_{7}<0$.

La ecuación (5) se estimó con la metodología de panel de datos considerando las variaciones porcentuales anuales de las variables incluidas durante el periodo 1996-2010, lo que permite trabajar con 84 observaciones: 14 periodos y 6 secciones cruzadas. Se corrieron varias especificaciones, primero sin incluir ningún tipo de efectos y luego asumiéndose efectos fijos y aleatorios en sección cruzada y en periodo; también se probó el uso de rezagos en algunas variables para corregir posibles problemas de endogeneidad o bien porque ello permitió resultados más robustos. En la selección del modelo correcto se aplicó primero el test de máxima verosimilitud, para elegir entre ausencia de efectos o efectos fijos, y posteriormente la prueba de Hausman, para decidir entre efectos fijos o aleatorios. En ambos casos se trata de un test de $\chi^{2}$, en el que la regla de decisión establece lo siguiente: en el test de máxima verosimilitud, si $\rho>0.05$, se acepta que los efectos fijos son redundantes y se prefiere el modelo que implica

\footnotetext{
${ }^{7}$ Alternativamente se utiliza TCA_OCUP_MAQUILA en lugar de TCA_OCUP_MANUF.
} 
ausencia de efectos; en el test de Hausman, si $\rho>0.05$, se acepta la hipótesis de que ambos modelos, de efectos fijos y aleatorios, son iguales, pero se prefiere este último por permitir más grados de libertad.

\section{Interpretación de resultados}

El primer paso fue determinar las especificaciones y el modelo correcto para estimar la ecuación (5), para lo cual se aplicaron las pruebas mencionadas. En todos los casos se rechazó el modelo sin efectos y se aceptó la hipótesis que plantea la igualdad entre el modelo de efectos fijos y el de aleatorios en periodo, en cuyo caso se debe optar por el segundo (cuadro 12).

Una vez definido el modelo correcto y dos especificaciones alternativas, se procedió a la estimación con la técnica de mínimos cuadrados generalizados, presentándose ambos modelos, el de efectos fijos en periodo y el de efectos aleatorios en periodo con fines comparativos. Al estimar el primero se establecieron ponderaciones en periodos con la finalidad de solucionar posibles problemas de autocorrelación y heterocedasticidad en los residuos. Cuando se estimó el segundo, se recurrió a alguna de las técnicas disponibles en Eviews para obtener errores corregidos por la presencia de heterocedasticidad. Los resultados de este ejercicio están disponibles en el cuadro 13.

Cuadro 12. Pruebas de selección del modelo con datos de panel

\begin{tabular}{lcccc}
\hline & $\begin{array}{c}\text { Efectos fijos } \\
\text { en sección } \\
\text { cruzada }\end{array}$ & $\begin{array}{c}\text { Efectos fijos } \\
\text { en periodo }\end{array}$ & $\begin{array}{c}\text { Efectos } \\
\text { aleatorios } \\
\text { en sección } \\
\text { cruzada }\end{array}$ & $\begin{array}{c}\text { Efectos } \\
\text { aleatorios } \\
\text { en periodo }\end{array}$ \\
\hline$\chi^{2}$ & 1.70 & 97.82 & n. d. ${ }^{*}$ & 3.60 \\
\hline $\begin{array}{l}\text { Especificación } 1 \\
\text { libertad }\end{array}$ & 5 & 12 & n. d. ${ }^{*}$ & 6 \\
\hline Probabilístico $(\rho)$ & 0.89 & 0.00 & n. d. ${ }^{*}$ & 0.73 \\
\hline$\chi^{2}$ & 1.09 & 81.37 & & 2.24 \\
\hline $\begin{array}{l}\text { Grados de } \\
\text { libertad }\end{array}$ & 5 & 12 & n. d. ${ }^{*}$ & 6 \\
\hline Probabilístico $(\rho)$ & 0.95 & 0.00 & n. d. ${ }^{*}$ & 0.90 \\
\hline
\end{tabular}

*El test de efectos aleatorios requiere que el número de secciones cruzadas sea mayor que el número de coeficientes estimados. 
38 ECONOMÍA: TEORÍA Y PRÁCTICA • Nueva Época, número 41, julio-diciembre 2014

Cuadro 13. Función de crecimiento del PIB por trabajador (efectos fijos en periodo)

\begin{tabular}{|c|c|c|c|c|}
\hline & $\begin{array}{c}\text { Especificación } \\
\text { 1a } \\
\text { Efectos } \\
\text { aleatorios en } \\
\text { periodo }\end{array}$ & $\begin{array}{c}\text { Especificación } \\
1 \text { 1a } \\
\text { Efectos fijos } \\
\text { en periodo }\end{array}$ & $\begin{array}{c}\text { Especificación } \\
2 a \\
\text { Efectos } \\
\text { aleatorios en } \\
\text { periodo }\end{array}$ & $\begin{array}{l}\text { Especificación } \\
2 b \\
\text { Efectos fijos } \\
\text { en periodo }\end{array}$ \\
\hline $\begin{array}{l}\text { Constante } \\
\qquad(t)\end{array}$ & $\begin{array}{c}2.68 \\
(1.43)\end{array}$ & $\begin{array}{l}2.83 * * \\
(1.92)\end{array}$ & $\begin{array}{l}1.76 \\
(0.87)\end{array}$ & $\begin{array}{l}1.94 * * \\
(1.71)\end{array}$ \\
\hline $\begin{array}{c}T C A \_I P T / P O \\
(t)\end{array}$ & $\begin{array}{l}0.03^{*} \\
(2.01)\end{array}$ & $\begin{array}{l}0.03^{*} \\
(2.23)\end{array}$ & $\begin{array}{l}0.04^{*} \\
(2.68)\end{array}$ & $\begin{array}{l}0.05^{\star} \\
(5.42)\end{array}$ \\
\hline$T C A \_E S C O L A R \_P E A(-1)$ & $\begin{array}{l}-0.93 \\
(-0.82)\end{array}$ & $\begin{array}{l}-1.20 \\
(-1.11)\end{array}$ & $\begin{array}{l}-0.67 \\
(-0.54)\end{array}$ & $\begin{array}{l}-0.91 \\
(-1.15)\end{array}$ \\
\hline$T C A \_O C U P \_P R I M(-1)$ & $\begin{array}{c}0.04 \\
(1.11) \\
\end{array}$ & $\begin{array}{c}0.05^{* *} \\
(1.71)\end{array}$ & $\begin{array}{c}0.05 \\
(1.31) \\
\end{array}$ & $\begin{array}{c}0.06 * * \\
(1.74)\end{array}$ \\
\hline $\begin{array}{c}T C A \_O C U P \_M A N U F(-1) \\
(t)\end{array}$ & $\begin{array}{c}0.31 * * \\
(1.90)\end{array}$ & $\begin{array}{l}0.43^{*} \\
(3.44) \\
\end{array}$ & & \\
\hline $\begin{array}{c}T C A \_O C U P \_M A Q U I L A(-1) \\
(t)\end{array}$ & & & $\begin{array}{l}0.06^{*} \\
(1.95)\end{array}$ & $\begin{array}{l}0.08^{*} \\
(2.43)\end{array}$ \\
\hline $\begin{array}{c}\text { TCA_OCUP_TERC } \\
(t)\end{array}$ & $\begin{array}{l}-0.41 * \\
(-3.69)\end{array}$ & $\begin{array}{l}-0.41 * \\
(-4.20)\end{array}$ & & \\
\hline $\begin{array}{c}T C A \_O C U P \_H O G A R \\
(t)\end{array}$ & & & $\begin{array}{l}-0.18^{*} \\
(-2.58)\end{array}$ & $\begin{array}{l}-0.18^{*} \\
(-2.76)\end{array}$ \\
\hline $\begin{array}{c}T M N(-1) \\
(t)\end{array}$ & $\begin{array}{l}-1.44^{*} \\
(-2.57)\end{array}$ & $\begin{array}{l}-1.49 * \\
(-2.93)\end{array}$ & $\begin{array}{l}-1.17^{*} \\
(-2.21)\end{array}$ & $\begin{array}{l}-0.93^{*} \\
(-2.05)\end{array}$ \\
\hline$R^{2}$ ajustada & 0.32 & 0.79 & 0.26 & 0.73 \\
\hline DW & 2.20 & 2.18 & 2.36 & 2.19 \\
\hline$F$ & 5.60 & 16.63 & 4.23 & 12.59 \\
\hline $\begin{array}{c}\text { Jarque Bera } \\
\rho\end{array}$ & $\begin{array}{l}10.58 \\
(0.01) \\
\end{array}$ & $\begin{array}{c}1.49 \\
(0.47) \\
\end{array}$ & $\begin{array}{l}11.49 \\
(0.00)\end{array}$ & $\begin{array}{c}2.72 \\
(0.26) \\
\end{array}$ \\
\hline$N$ & 78 & 78 & 78 & 78 \\
\hline
\end{tabular}

*Significativo por lo menos al $5 \%$; **significativo al $10 \%$.

La estimación revela varias situaciones que en el análisis de los datos no eran evidentes: en primer lugar, el rol de la inversión pública como fuente de diferencias en las tasas de crecimiento estatal, a través de un vínculo positivo que ha favorecido a aquellos estados en donde ésta ha crecido más, resultado que es consistente con lo encontrado por Fuentes y Mendoza (2003) aunque su ejercicio se refiere a todo el país y corresponde a un estudio sobre convergencia/divergen- 
cia regional. Este hallazgo que podría parecer obvio, no lo es tanto si se considera que existen posiciones en el medio académico que defienden la hipótesis de que la inversión pública ejerce un efecto de desplazamiento sobre la inversión privada (crowding out). Si éste fuese el caso, la expansión de la primera no impulsaría el crecimiento, pues la segunda lo reduciría en la misma proporción; por tanto, el signo positivo y la significación estadística del coeficiente $\alpha_{1}$ asociado a TCA_IPT/ Po es también un argumento en contra de dicha hipótesis y a favor de que existe un efecto de inducción de la inversión pública (crowding in), o por lo menos de que el desplazamiento, si existe, es incompleto. Esto es verdad sobre todo cuando el gasto gubernamental se destina a proveer infraestructura productiva.

Con respecto a la variable TCA_ESCOLAR_PEA, que trata de capturar el efecto asociado con la acumulación de capital humano mediante el parámetro $\alpha_{2}$, su baja significación estadística y signo negativo expresan un impacto nulo sobre el crecimiento, lo cual podría reflejar errores de medición en la construcción de dicha variable o la baja calidad que caracteriza a una porción alta del sector educativo. La falta de impacto de los logros educativos ya se advertía en los datos revisados, en los que se observan indicadores de escolaridad y cobertura que se expanden rápidamente sin que se registre un incremento proporcional en la tasa a la que crece el PIB per cápita. La explicación remite a una ausencia de oportunidades en la esfera productiva para emplear eficaz y eficientemente una fuerza de trabajo cada vez más calificada, lo que hace pensar en una escasez de inversiones demandantes de mano de obra educada (Easterly, 2002).

Los coeficientes estimados para las medidas indirectas de la especialización muestran un impacto positivo de las actividades primarias, $\alpha_{3}>0$, que puede explicarse por el alto nivel de tecnificación que ha alcanzado el agro en el norte de México. Por su parte, los beneficios de la industrialización se confirman al obtenerse valores positivos y significativos para $\alpha_{4}$, ya sea que se utilice TCA OCUP_MANUF O TCA_OCUP_MAQUILA, aunque el tamaño del coeficiente es considerablemente mayor en el primer caso, evidenciando las ventajas de contar con una industria integrada a las cadenas productivas locales. Con respecto a los sectores terciario y del hogar, se tiene que $\alpha_{5}$ y $\alpha_{6}$ son negativos probablemente porque concentran muchas actividades tradicionales de bajo valor agregado y poco dinámicas en el producto por trabajador, aunque otra interpretación podría ser que su expansión se alimentó con flujos laborales provenientes de otros sectores con mayor productividad.

En cuanto a la migración, los resultados econométricos confirman su efecto negativo sobre la productividad del trabajo $\left(\alpha_{7}<0\right)$, situación que se expli- 
ca por su composición social, en la que predominan familias de bajos recursos y con escaso acervo educativo, pero también por la insuficiencia de las inversiones para absorber los flujos crecientes de fuerza laboral en empleos mediana o altamente productivos. Como consecuencia de ello, la migración ha alentado el incremento de la subocupación, la informalidad y la ocupación en actividades de subsistencia.

\section{CONCLUSIONES}

Los resultados de esta investigación muestran la complejidad económica que caracteriza a la frontera norte de México, encontrándose que las diferencias en las trayectorias del PIB per cápita y del PIB por trabajador no obedecen a un patrón único y generalizable; por el contrario, pareciera que en cada caso los determinantes de dicha trayectoria responden a condiciones y factores distintos. Por ejemplo, Tamaulipas, Sonora y Coahuila se beneficiaron de una relativamente alta inversión pública que no generó ventajas similares en las otras entidades. En casi toda la región se consolidó un sector agropecuario fuerte y productivo que favoreció el crecimiento, con especial fuerza en Sonora; la excepción fue Baja California que, paradójicamente, fue también el único estado en donde aumentó el peso relativo de estas actividades dentro del empleo estatal. La industria manufacturera incrementó su peso relativo dentro de la estructura económica sólo en Sonora y Tamaulipas, con lo que impulsó su buen desempeño, mientras que el resto de las entidades vieron decrecer su importancia relativa.

Aunque la región en su conjunto entró en un proceso de "terciarización", ello no tuvo efectos tan adversos en Chihuahua y Nuevo León, en donde incluso éstos pudieron haber sido positivos si se considera que el producto por trabajador en este sector se situó muy por encima del promedio regional y nacional. Por otro lado, la expansión de la informalidad y de los servicios relacionados con el hogar inhibió el crecimiento en todos los estados, pero de acuerdo con su magnitud fue menos grave en Chihuahua y Tamaulipas y sus mayores repercusiones negativas se dieron en Baja California. En lo que respecta al crecimiento demográfico, éste jugó en contra de Baja California y Nuevo León, en el primer caso alimentado fuertemente por los flujos migratorios. La migración inhibió el crecimiento en las áreas receptoras, no sólo por su impacto en el tamaño de la población, sino también porque alentó una recomposición en la estructura del empleo con un mayor peso de las ocupaciones tradicionales y de subsistencia. El único estado que tuvo una TMN positiva a lo largo del periodo de estudio fue Baja Cali- 
fornia, lo que explica en buena medida su pobre desempeño económico. Por último, es importante destacar que, al igual que ocurrió en todo el país, en la frontera norte no se lograron generar condiciones propicias para aprovechar el gran esfuerzo educativo realizado en las últimas décadas y que aceleró considerablemente la acumulación de capital humano.

Un aspecto relevante con relación al impacto que tiene la estructura productiva sobre el desempeño económico son las amplias diferencias encontradas entre los niveles de productividad y las tasas de crecimiento para un mismo sector en diferentes estados. En la medida en que éstas no pueden atribuirse a brechas en la formación de capital humano, la explicación podría buscarse en los desiguales niveles y ritmos con que se acumula capital físico. Asimismo, se puede argumentar que la composición de actividades por sector es considerablemente distinta de un estado a otro, por lo que el término industrialización o "terciarización" tiene significado e implicaciones muy distintas en cada uno de ellos, esto es, un proceso tal puede acompañarse con una tasa de crecimiento alta o modesta, dependiendo de cuáles ramas o clases de actividad económica predominen.

Los hallazgos de esta investigación sugieren que el desarrollo de la región no sólo requiere una reactivación de la función gubernamental como proveedor de infraestructura productiva, sino también una reorientación en los procesos de especialización hacia actividades con rendimientos crecientes. Con respecto al capital humano, se puede afirmar categóricamente que éste no representa en la actualidad una restricción al crecimiento, toda vez que se han hecho esfuerzos muy importantes en educación y en la formación de personal calificado. El problema principal es encontrar estrategias para aprovechar eficientemente la oferta disponible de este factor, lo cual nos remite al tema de la especialización, pues se requiere impulsar sectores y actividades económicas que hagan uso intensivo de este recurso. Finalmente, es importante destacar la necesidad de que se revise el pacto federal para buscar mecanismos de compensación que apoyen a las entidades federativas que registran saldos migratorios positivos, pues si bien éstas contribuyen a despresurizar las tensiones laborales y sociales de otros estados, lo hacen sacrificando su propio desempeño económico y con un deterioro en sus indicadores de bienestar social.

\section{REFERENCIAS BIBLIOGRÁFICAS}

CONAPO (s.f.), "Migración interna", en SEGOB/CONAPO. Consultado el 20 de mayo de 2012, en: http://www.conapo.gob.mx/es/CONAPO/Migracion_Interna. 
Domar, Evsey (1946), “Capital expansion, rate of growth and employment”, Econometrica, 14 (2), pp. 137-147.

Easterly, Williamn (2002), The Elusive Quest for Growth. Economists' Adventures and Misadventures in the Tropics, London, The MIT Press.

Fuentes, Noé, y Mendoza, Eduardo (2003), "Infraestructura pública y convergencia regional en México, 1980-1998", Comercio Exterior, 53 (2), febrero, pp. 178-187.

Grossman, Gene, y Helpman, Elhanan (1991), Innovation and Growth in the Global Economic, Cambridge, MIT Press.

Harris, John, y Todaro, Michael (1970), "Migration, unemployment and development: A two-sector analysis", American Economic Review, 60 (1), pp. 126-142.

Harrod, Roy (1939), “An essay in dynamic theory”, The Economic Journal, 49 (193), marzo, pp. 14-33.

INEGI (s.f.a), "Banco de Información Económica", en Instituto Nacional de Estadística y Geografía. Consultado el 14 y el 16 de mayo, y el 12 de junio de 2012, en: http://www.inegi.org.mx/sistemas/bie/.

_ (s.f.b), "Censos y Conteos de Población y Vivienda", en Instituto Nacional de Estadística y Geografía. Consultado el 14 y el 31 de mayo de 2012, en: http:// www.inegi.org.mx/est/contenidos/proyectos/ccpv/default.aspx.

_ (s.f.c), "Encuesta Nacional de Ocupación y Empleo (ENOE)", en Instituto Nacional de Estadística y Geografía. Consultado el 16 de mayo de 2012, en: http:// www.inegi.org.mx/est/contenidos/proyectos/encuestas/hogares/regulares/enoe/ default.aspx.

Kaldor, Nicholas (1957), “A model of economic growth”, The Economic Journal, 67 (268), diciembre, pp. 591-624.

- (1966), Causes of the slow rate of economic growth of the United Kingdom: an inaugural lecture, Cambridge, Cambridge University Press.

- (1970), “The case for regional policies”, Scottish Journal of Political Economy, 17 (3), noviembre, pp. 337-348.

Kremer, Michael (1993), "Population Growth and Technological Change: One Million BC to 1990”, Quarterly Journal of Economics, 108 (3), agosto, pp. 681-716.

León, Adrián de (2000), "Patrones de crecimiento regional y su impacto en la productividad mexicana", El Mercado de Valores, Lx (10), octubre, pp. 35-44.

- (2008), "Cambio regional del empleo y productividad manufacturera en México. El caso de la frontera norte y las grandes ciudades: 1970-2004”, Frontera Norte, 20 (40), julio-diciembre, pp. 79-103.

Lewis, W. Arthur (1954), "Economic Development with Unlimited Supplies of Labor", Manchester School of Economic and Social Studies, 22 (2), pp. 139-191. 
Lucas, Robert Jr. (1988), "On the mechanics of Economic Developments", Journal of Monetary Economics, 0 (22), pp. 3-42.

Mendoza, Eduardo (2002), "Agglomeration economies and urban manufacturing growth in the northern border cities of Mexico", Economía Mexicana, XI (1), primer semestre, pp. 163-190.

Moreno-Brid, Juan Carlos, y Ros, Jaime (2009), Development and Growth in the Mexican Economy, Oxford, Oxford University Press.

Myrdal, Gunnar (1970), Teoría económica y regiones subdesarrolladas, México, Fondo de Cultura Económica.

North, Douglas (1990), Institutions, Institutional Change and Economic Performance, New York, Cambridge University Press.

Obregón, Carlos (2008), Teorías del desarrollo económico, México, Pensamiento Universitario Iberoamericano.

Ocegueda, Juan Manuel (2000), Crecimiento y desarrollo económico. El estado actual del debate, Mexicali, Universidad Autónoma de Baja California.

Ocegueda, Juan Manuel; Escamilla, Antonio, y Mungaray, Alejandro (2011), "Estructura productiva y tasa de crecimiento en la frontera norte de México", Problemas del Desarrollo, 42 (164), enero-marzo, pp. 71-97.

Presidencia de la República (s.f.a), "Informes de Gobierno", en Presidencia de la República. Consultado el 20 de mayo de 2012, en: http://calderon.presidencia.gob. $\mathrm{mx} /$ multimedia/biblioteca-digital/informes-de-gobierno/

_ (s.f.b), "Vicente Fox", en Presidencia de la República. Consultado el 20 de mayo de 2012, en: http://fox.presidencia.gob.mx/vicentefox/.

Rodrik, Dani (2008), One Economics, Many Recipes. Globalization, Institutions and Economic Growth, Princeton University Press.

Romer, Paul (1986) "Increasing returns and long run growth", Journal of Political Economy, 94 (5), octubre, pp. 1002-1037.

- (1990), "Endogenous technological change", Journal of Political Economy, Num. 98 (5), pp. s71-s 102.

Ros, Jaime (2004), La teoría del desarrollo y la economía del crecimiento, México, Centro de Investigación y Docencia Económica-Fondo de Cultura Económica.

Rosenstein-Rodan, Paul (1943), "Problems of Industrialisation of Eastern and SouthEastern Europe", The Economic Journal, 53 (210/211), junio - septiembre, pp. 202-211.

Rostow, Walter (1960), The Stages of Economic Growth, a Non-Communist Manifesto, Cambridge, University Press. 
44 ECONOMÍA: TEORÍA Y PRÁCTICA • Nueva Época, número 41, julio-diciembre 2014

Rowthorn, Robert, y Ramaswamy, Ramana (1997), "Deindustrialization: causes and implications", International Monetary Fund Working Paper 97/42.

SEP (s.f.), "Sistema Nacional de Información Estadística Educativa", en SEP. Consultado el 5 de junio de 2012, en: http://www.snie.sep.gob.mx/indicadores_y_ pronosticos.html.

Solow, Robert (1956), "A Contribution to the Theory of Economic Growth", The Quarterly Journal of Economics, 70 (1), febrero, pp. 65-94.

Thirlwall, Anthony (1979), "The balance of payments constraint as an explanation of international growth rate differences", Banca Nazionale del Lavoro Quarterly Review, 32 (128), pp. 45-53.

Thirlwall, Anthony, y Dixon, Robert (1979), “A model of export-led growth with balance of payments constraint", en J. Bowers (ed.), Inflation, Development and Integration, Leeds, Leeds University Press, pp. 173-192. 